\title{
An autonomous low-power instrument platform for monitoring water and solid discharges in mesoscale rivers
}

\author{
Guillaume Nord $^{1}$, Yoann Michielin ${ }^{1}$, Romain Biron ${ }^{1}$, Michel Esteves ${ }^{1}$, Guilhem Freche ${ }^{1}$, Thomas Geay ${ }^{2}$, \\ Alexandre Hauet ${ }^{3}$, Cédric Legoût ${ }^{1}$, and Bernard Mercier ${ }^{1}$ \\ ${ }^{1}$ Univ. Grenoble Alpes, CNRS, IRD, Grenoble INP, IGE, 38000 Grenoble, France \\ ${ }^{2}$ Univ. Grenoble Alpes, CNRS, Grenoble INP, GIPSA-lab, 38000 Grenoble, France \\ ${ }^{3}$ Electricité de France, DTG, Grenoble, France
}

Correspondence: Guillaume Nord (guillaume.nord@univ-grenoble-alpes.fr)

Received: 25 September 2019 - Discussion started: 23 October 2019

Revised: 27 January 2020 - Accepted: 29 January 2020 - Published: 17 March 2020

\begin{abstract}
We present the development of the River Platform for Monitoring Erosion (RIPLE) designed for monitoring at high temporal frequency $(\sim 10 \mathrm{~min})$ of water discharge, solid fluxes (bedload and suspended load) and properties of fine particles (settling velocity) in mesoscale rivers, i.e. which drain mesoscale catchments $\left(\approx 10-10^{3} \mathrm{~km}^{2}\right)$. This platform responds to a request to continuously measure these variables in rivers using a single, centralized device, and to do this in the most direct way possible. The platform integrates the following instruments: (i) for water discharge, water level radar, and surface velocity radar, digital cameras and an echo sounder; (ii) for fine sediment load, turbidimeters and automatic samplers including the SCAF (a sediment settling velocity characterization device); (iii) for bedload, a hydrophone; and (iv) for water quality, a conductivity probe and water sampling. As far as water discharge monitoring is concerned, priority has been given to non-intrusive instruments to improve the robustness of the system. All the instruments are driven by a data logger (Campbell ${ }^{\circledR}$ CR6), which locally stores the data and then uploads them to a remote server every hour during the day using a 3G modem. SMS (Short Message Service) alerts can be sent depending on scheduled conditions (e.g. low battery voltage, water level threshold, all samples of the automatic sampler collected). The platform has been designed to be as autonomous as possible: it is powered by a battery that is supplied by a solar panel. Limiting the power consumption of the platform was one of the main technical challenges because of the quantity of instruments integrated. A simple $100 \mathrm{~W}$ solar panel is sufficient to power the entire platform, even during win-
\end{abstract}

ter or low insulation conditions. A user-friendly interface has been developed, enabling to visualize the data collected by the platform from an internet connection. It is also possible to remotely configure the platform within this interface, e.g. to modify water sampling thresholds or alert thresholds. Finally, the platform is relatively easy to move from one site to another, because its installation requires little civil engineering. To date, RIPLE has been tested on two rivers of the Alps in France: the Romanche river in Bourg d'Oisans from September 2016 to July 2018 and the Galabre river in La Robine sur Galabre since October 2018, demonstrating the proper functioning of the platform.

\section{Introduction}

Sediment transport has an impact on the ecological status of water bodies, the morphological dynamics of the river, the stability of river banks and structures, and many human activities such as energy production and drinking water supply (Renwick et al., 2005; Lee and Foster, 2013). Two modes of transport are classically considered: bedload and suspended load (Julien, 1995). Bedload consists of coarse particles transported by sliding, rolling or saltation on the bottom of the river. Suspended load refers to the transport of fine particles through the turbulent field within the water column. In this study, suspended load applies for particles finer than $2 \mathrm{~mm}$. The river sediment material is generally a mixture of coarse and fine particles that can interact together in relation to hydrology (the succession of floods and low flows), 
vegetation and human activities (material extraction, riverbed modification, presence of dams and weirs) (Corenblit et al., 2007). The transfer of coarse and fine particles downstream can lead to progressive siltation of structures, such as hydroelectric power plants (Morris and Fan, 1998; Walling and Fang, 2003), or to degradation of river quality by clogging the bottom or by direct attack on the respiratory organs of fish species (Owens et al., 2005). Alternatively, high-energy rivers with insufficient supply of sediment load can lead to erosion of the main channel (Frings et al., 2014). Suspended sediments are also a privileged vector for the transport of nutrients $(\mathrm{C}, \mathrm{N}, \mathrm{P})$ or contaminants (pesticides, metals, organic products, microorganisms). Finally, the increase in turbidity leads to significant costs for water treatment when it is used as drinking water (Sobieszczyk, 2007). Overall, there is a need for systems that are able to monitor water and solid discharges in rivers, and these systems should take into account both fine and coarse sediments.

High-frequency monitoring of water and solid discharges is also a key element for the scientific community interested in the functioning of the critical zone (earth's near surface) in response to global changes (climatic change, land use and land cover changes). The understanding of the critical zone requires a holistic approach involving the monitoring of a combination of variables such as hydrological, chemical and biological variables (Brantley et al., 2016; Gaillardet et al., 2018) in different compartments of the catchment, i.e. soil, groundwater, river, surface-atmosphere interface and vegetation. One of the main issues for the people working on the critical zone is the determination of mass balance of water and associated matter and energy balances. The fluxes exported through the river system are of primary importance as the river collects a large part of the surface and subsurface flows within the catchment. There has been a recent attempt by the French critical zone community (Gaillardet et al., 2018) to develop a list of variables to be monitored continuously in each of the compartments of the critical zone. For rivers, this list includes variables such as flow discharge, electrical conductivity, temperature, turbidity, suspended sediment concentration (SSC), and chemical and isotopic composition of the water.

Estimates of suspended sediment flux are usually obtained by multiplying the water discharge by the SSC, typically expressed in grams per litre of the mixture of water and suspended sediment. High-frequency SSC monitoring is required for reliable estimates of the suspended sediment flux. Nevertheless, a reliable and easy method to obtain a direct, continuous SSC measurement is not currently available. Alternatively, a proxy of the SSC, which can be easily monitored continuously and related to SSC, is employed. The most commonly used proxy to date is turbidity (Gray and Gartner, 2009; Rasmussen et al., 2009; Navratil et al., 2011). In turbulent rivers, it is assumed that the SSC is relatively homogeneous within the cross section. Therefore, a point measurement of turbidity from the river bank is acceptable.
This is easily the case in rivers where the slope of the bed is greater than $0.1 \%$ (Mano, 2008; Navratil et al., 2011) and for silt-sized particles or finer. However, this assumption is questionable for sand-sized particles (Camenen et al., 2019), and there is no reference method for sand-sized particles to date. The turbidity-SSC rating curve is established from direct measurements of SSC that are performed through automatic water sampling. Samples collected at regular intervals or when thresholds are exceeded (e.g. water level, turbidity) are manually retrieved during site visits and brought to the laboratory. They are then analysed to measure the SSC using the filtration method (for low SSC, typically $<2 \mathrm{~g} \mathrm{~L}^{-1}$ ) or the total evaporation method (for higher SSC) (Navratil et al., 2011; Nord et al., 2014; ISO 4365). A global turbidity-SSC rating curve can be established using all direct SSC measurements performed at a station, and this allows the turbidity time series to be converted into the SSC time series. However, in headwater catchments where sediment sources can vary rapidly during a flood, it is strongly recommended to perform a specific calibration for each flood to reduce measurement uncertainty (Navratil et al., 2011). Indeed, turbidity is very sensitive to particle size and also to the shape and colour of the particles.

High-frequency bedload sampling is required for reliable estimates of the bedload flux since bedload transport is a very dynamic process and can even be discontinuous through the occurrence of intermittent pulses (Aigner et al., 2017). However, bedload samplings are very challenging to perform continuously over long periods. Alternatively, hydraulic-based equations are mostly used to compute bedload sediment budget (e.g. Recking et al., 2012), but their reliability is sometimes questionable (Gray and Simões, 2008). In the last decades, several proxies were used to get a continuous monitoring of bedload processes with surrogate methods (Gray et al., 2010). Among these methods, three of them do not need the installation of heavy, dedicated structures in the stream flow: (i) acoustic Doppler current profiler (aDcp), (ii) passive acoustic monitoring, and (iii) seismic monitoring. The aDcp can be used to measure an apparent bedload velocity which is related to bedload fluxes (Rennie et al., 2002, 2017). However, the deployment of an aDcp operating from the surface is not appropriate in the case of rivers with steep slope (typically $>1 \%$ ), because the presence of waves at the surface of the water hinders the measurement, and floating objects transported during floods may damage the device. Passive acoustic and seismic monitoring record the noises that are naturally generated by bedload transport when impacting the riverbed (Thorne and Foden, 1988; Tsai et al., 2012). Passive acoustic monitoring is achieved with hydrophones that sense the acoustic waves propagating under water. The acoustic power of bedload sounds has been related to bedload fluxes by using site-specific calibration curves in gravel-bed rivers (Marineau et al., 2016; Geay et al., 2017a). Seismic monitoring is achieved with geophones or seismometers which record the seismic waves propagating in the soil layer (sur- 
face waves). Similarly, the power of bedload seismic noises has been related to bedload fluxes in laboratory experiments (Gimbert et al., 2018) and partially in field experiments (Roth et al., 2016). Acoustic and seismic monitoring provide continuous proxies that are related to bedload fluxes, but these proxies are also dependent on additional bedload parameters (i.e. grain size distribution, bedload kinematics) and on processes related to wave propagation (Geay et al., 2017b). To date, whatever the indirect method used, and calibration efforts with direct bedload samplings are needed to elaborate rating curves and to finally provide a continuous monitoring of bedload fluxes.

Knowledge of water discharge is essential whether it is for estimating suspended sediment fluxes, dissolved matter fluxes, or nutrient or contaminant fluxes associated with fine particles. The monitoring of water discharge is not easy, especially in mountainous rivers where flow discharge can vary by several orders of magnitude in a few hours (Borga et al., 2014) and solid discharges can demonstrate a hysteretic and transitory behaviour, more impulsive than the flow itself, resulting in significant changes in the morphology of the river. Therefore, monitoring discharge deserves a special attention. The conventional monitoring of flow discharge involves the measurement of a primary variable such as water depth or water level. A calibration curve, the so-called stage-discharge rating curve, is usually established based on information such as gauging (punctual discharge measurements performed using different techniques such as slug injection of a tracer in solution, impeller or electromagnetic current meter, aDcp, handheld surface velocity radar gun) or hydraulic modelling to convert the water level time series into flow discharge time series (World Meteorological Organization, 2010; Tomkins, 2012). This work typically involves substantial human and financial effort. It is indeed very demanding to mobilize a technical work force to carry out gauging. Moreover, the mobilization of a work force during floods is not without risk for the operators. It is also not so frequent to be present in the field during the biggest hydrological events. Finally, when a morphogenic flood occurs, the changes of the river geometry implies that we should start over the calibration curve. Thus, new methods are required to provide more direct access to the water discharge (without using the stage-discharge rating curve) and therefore reduce the field work related to gauging and bathymetry surveys. These methods involve the use of other variables in addition to the water level.

The first variable that has been added to hydrometric stations is velocity. During the last decade, the introduction of fixed flow velocity monitoring systems (transit time ultrasonic flowmeters, acoustic Doppler current profiler horizontal ( $\mathrm{H}-\mathrm{aDcp})$ and vertical ( $\mathrm{V}-\mathrm{aDcp})$, surface velocity radars) into hydrometric station equipment has gradually become more widespread (Costa et al., 2006; Levesque and Oberg, 2012; Nord et al., 2014; Thollet et al., 2017). These systems all provide a more or less local monitoring of flow veloc- ity. More recently, systems using cameras and the large-scale particle imagery velocity (LSPIV) method have been developed and deployed in the field to estimate the surface velocity field (Hauet et al., 2008; Leduc et al., 2018; Le Coz et al., 2010; Muste et al., 2008; Stumpf et al., 2016). These systems provide field data of velocity on a stretch of river. Whether it is fixed flow velocity monitoring systems or LSPIV systems, there is no direct access to the mean channel velocity, which is the variable of interest to estimate directly the flow discharge by multiplying the mean channel velocity by the cross-sectional flow area. Thus the development of innovative methods is necessary to estimate the mean channel velocity from surrogate monitoring. The first attempts concern the index velocity method, but this approach is still largely based on the use of gauging (Levesque and Oberg, 2012; Morlock et al., 2002). Continuous monitoring of the crosssectional flow area by a direct method is not possible to date because of the lack of dedicated technology. Alternatively, a relation between stage and channel area, called a "stage-area rating" is established based on topographic surveys, which are repeated typically once a year or after each morphogenic flood. Changes in the water-level-velocity relationship make it possible to detect changes in the bathymetry and the need to survey new bathymetry of the section (Thollet et al., 2017).

Therefore, being able to carry out high-frequency monitoring of water and solid discharges in any river and at any site of convenience is a high expectation for both operational and research applications. This should make it possible to extend the monitoring to isolated sites that have not yet been gauged, i.e. in environments that may be remote, difficult to access, under potentially extreme conditions (humidity, temperature, wind, radiation) or subject to destructive phenomena (cyclone, floods, vandalism, etc.). The availability of power, continuous data transmission and possible remote configuration remains a challenge in these environments. There are studies that have developed autonomous monitoring platforms in hostile environments to remain unattended for several months or years (Musko et al., 2009; Clauer et al., 2014; Peters et al., 2014; Morschhauser et al., 2017), but few or none for monitoring of water and solid (both fine and coarse particle) discharges in rivers (Mueller et al., 2013; Navratil et al., 2011; Comiti et al., 2014; Griffiths et al., 2014).

This study presents the development of a multiinstrumental platform called RIPLE (River Platform for Monitoring Erosion). The different variables measured relate to the flow discharge, water quality, fluxes of fine and coarse sediment, and optionally the properties of suspended fine sediments (settling velocity). A user interface is also presented that enables data visualization and remote configuration of the platform. A case study is described to validate the platform's operation. 
G. Nord et al.: An autonomous low-power instrument platform for monitoring water

\section{Design consideration}

The development of RIPLE is preferably aimed at mesoscale rivers, with potentially high SSC values (peak values typically between 1 and $100 \mathrm{~g} \mathrm{~L}^{-1}$ ), flow discharge ranging over several orders of magnitude in a short period of time (from $10^{-2}$ to $10^{2} \mathrm{~m}^{3} \mathrm{~s}^{-1}$ ) and bedload particles composed of a variety of grains from sand to cobbles or even boulders. However, it should be noted that the proposed instrumentation could be applied directly or after some modifications to lowland rivers and/or larger rivers. The choice was made to integrate instruments into the platform with a level of development that allows them to be easily assembled and to include recently developed instruments in the laboratory as commercially available equipment do not yet exist. Priority was given to non-intrusive instruments because of their robustness. Indeed, floods may produce important damage or destructions to any device present in the water. However, if non-intrusive instruments are commonly available for hydrometric applications, they do not really exist for the monitoring of sediment fluxes in this type of environment. The minimum set of variables to be integrated into the platform is as follows: (i) surface velocity and water level for hydrometry; (ii) water conductivity, temperature, and water sampling for water quality; (iii) turbidity and SSC via water sampling for suspended sediment; and (iv) acoustic power and elevation of the riverbed for bedload. A staff gauge and a control camera are also required to establish a local elevation reference frame and check the general state of the platform. All instruments should be controlled by a central control system.

The platform should allow for interaction between the different measurements (enabling triggering conditions to be activated and easily parameterized), data storage, remote data transfer, sending alarms, and remote and real-time management. In addition, the platform should be autonomous in energy and easily movable from one site to another. The different functions taken into account in the development of this platform are shown in the diagram of Fig. 1.

The sections presented in the following correspond to the sequential tasks that have been performed during the development of the platform: (1) the definition of the architecture and the choice of the acquisition and control system; (2) the development of an integrated solution (definition, development, test and formalization of protocols; power supply; sensor electronics; data storage; remote data transfer; enclosure and mechanics; and control software); (3) the development of a software interface allowing remote archiving and visualization of data and maintenance of the platform by sending new programs to modify the operation of the control system and the interaction between measurements; and (4) the deployment of the platform in the field for test and validation.

\section{System design}

\subsection{Control system}

The instruments integrated into RIPLE are listed in Table 1. They are sorted according to the type of measurement they provide: hydrometry, water quality, suspended load and bedload. The name of the variable, the physical principle of the measurement, the name of the model, the name of the manufacturer and the integration status in RIPLE are given for each instrument. A detailed description of each instrument is given in Sect. 3.3. All instruments are produced and marketed by manufacturers with the exceptions of the optic fibre turbidimeter (the so-called "capteur marseillais") for high turbidity and PASS (automatic water sampling), which are developed in public research laboratories and individually manufactured at the moment. The SCAF (a sediment settling velocity characterization device) has recently been marketed by the Aqualabo company. Two instruments, i.e. PASS (automatic water sampling) and SCAF, are now integrated into RIPLE but were not included in the case study presented in Sect. 6. Therefore, they appear as optional in Table 1.

The devices integrated into RIPLE are all controlled by the Campbell CR6 data logger (Fig. 2). This data logger was chosen because of its robustness in isolated sites and under difficult environmental conditions (humidity, temperature) and its flexibility in terms of ports (universal ports), e.g. Ethernet port, Secure Digital (SD) memory card slot and a large number of possible expansion modules (CDM-A108: analogue expansion module, SDM-SIO1A: RS-232, RS-485, RS-422 expansion modules), enabling users to control the large number of instruments integrated. This control system has a wireless connection option, allowing users to remotely control the system from the car or from a shelter during bad weather. The type of communication with each instrument is shown in Fig. 2. The other technical elements necessary for the operation of the platform are a solar panel, a solar regulator, a battery and a modem.

The sampling period of the platform is $10 \mathrm{~min}$, which is a good compromise between saving energy and obtaining a good description of water and sediment flux temporal variability in mesoscale rivers (Navratil et al., 2011). During the day, data are streamed every hour via a 3G/GPRS modem to the server located in the laboratory in Grenoble, and a digital control image is also transmitted. The modem is switched off at night to limit power consumption. For sites where a 3G connection would not be available, it is possible to switch to a $2.5 \mathrm{G}$ connection. The $2.5 \mathrm{G}$ connection is still acceptable for ASCII data, but it should be kept in mind that few images can be transmitted in this case. Alternatively, a satellite connection could be considered while taking into account the higher subscription cost. 


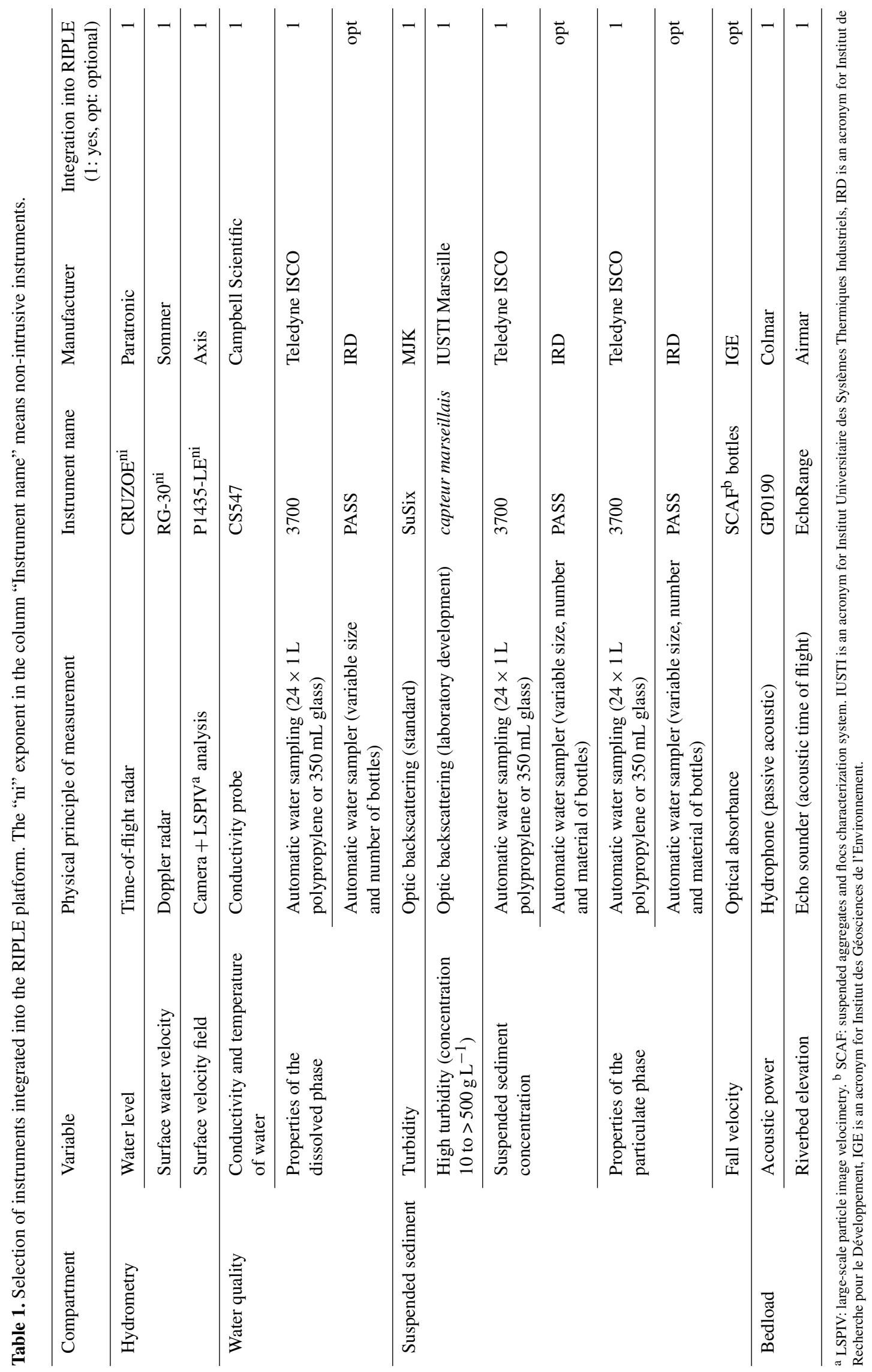




\subsection{Power supply}

RIPLE is powered by a combination of battery and photovoltaic panel to make it autonomous in energy, and it can be installed in a wide range of sites, even if there is no wired power grid. The power of the solar panel must be checked for each installation according to the sunshine on the site (latitude and elevation of the site, orientation and angle of the panel, presence of masks).

In Table 2, the details of the power balance is displayed for the case study presented in Sect. 6. The total consumption of the platform was estimated at $7758 \mathrm{mAh} \mathrm{d}^{-1}$ or $97.7 \mathrm{Wh} \mathrm{d}^{-1}$. This calculation takes into account a 10 min sampling period for most of the instruments, except the cameras which are switched on only every hour. Furthermore, the calculation is made with a sampling of 24 bottles during a single day. The data logger, which operates continuously, has the largest energy consumption, followed by the automatic sampler. Considering an autonomy of the battery of $5 \mathrm{~d}$, which means a period of $5 \mathrm{~d}$ without any solar input, and a battery level that should not fall below $25 \%$ of its capacity, we obtain a capacity of $51.7 \mathrm{Ah}$. Considering an additional safety factor of $65 \%$, the minimum battery capacity is $80 \mathrm{Ah}$. The selected battery model is a Sonnenschein Dryfit Solar Block SB 12/100 Ah. The Photovoltaic Geographical Information System (PVGIS) proposed by the European Commission (http: //re.jrc.ec.europa.eu/pvgis/, last access: 11 March 2020) was exploited to define the power of the photovoltaic panel to be used in combination with the battery of $100 \mathrm{Ah}$. The results showed that a photovoltaic panel of $100 \mathrm{~W}$ was sufficient to comply with the criteria of charge of the battery (at least $25 \%$ of its capacity), even in the middle of winter when the radiation is at its lowest. A photovoltaic panel (Sunmodule SW 100 poly RIB, $100 \mathrm{~W}$ ) and a solar regulator (STECA PR1010 10A/12-24V) were therefore selected.

\subsection{Sensors}

The different instruments integrated into the RIPLE platform are presented in Table 1 and Fig. 2. This section aims to provide more detailed information on each of the sensors and equipment.

\subsubsection{Control camera}

The aerial control camera acts as a webcam, allowing users to remotely visualize the instruments and the river. The camera can help to make a remote diagnosis in case of malfunctioning of the platform. The camera is an AXIS P1427-E. Its selection was based on various criteria such as image quality, zoom and focus, power consumption, robustness to the environment, and transfer of the images in real time. The maximal image resolution of the camera is 5 MP (megapixel). Tests in the lab have shown that the image resolution should be at least 3 MP to allow for details to be seen by zooming in the image. The minimum-to-maximum focal lengths of the zoom lens are $2.8-9.8 \mathrm{~mm}$. The lens has a fixed aperture of $f / 1$.6. The horizontal angle of view ranges between 27 and $92^{\circ}$. A wide horizontal angle of view (at least 80 to $100^{\circ}$ ) is required to get an overview of the site and of all the sensors. It means that the entire section of the river on which the platform is located and the adjacent river reach (about $10 \mathrm{~m}$ upstream and downstream) should be visible in the image. This makes it possible to understand the hydraulic behaviour of the river reach under all water level conditions. The control camera is usually installed at the opposite river bank to the staff gauge in order to see both the staff gauge and most of the sensors. The power consumption of the camera is $5 \mathrm{~W}$, and it can be turned off while it is not taking pictures. The camera has support for HTTP (Hypertext Transfer Protocol), UDP (User Datagram Protocol) and FTP (File Transfer Protocol). The camera is connected to a Power over Ethernet $(\mathrm{PoE})$ injector, which in turn is connected to the data logger via an Ethernet cable (see Fig. 2). The PoE injector is connected to the power supply $(12 \mathrm{~V})$. The data logger controls a relay that supplies power to the PoE injector. In terms of protection against solids and liquids, the enclosure of the camera complies with the Ingress Protection IP66. The camera can operate from -30 to $50^{\circ} \mathrm{C}$ and with relative humidity between $10 \%$ and $100 \%$ (including condensation).

The triggering of the acquisition is programmed as follows: (i) the camera is started by the data logger only during daytime via the electrical relay (typically once an hour); (ii) the camera takes a picture at the end of a 2 min heating period; (iii) the camera sends the picture to an FTP address via the data logger and also locally records a copy of the image on its 64 GB SD memory card; and (iv) the camera is switched off via the relay.

Ideally, it would have been possible to zoom in and even orient the camera remotely. However, these specifications were not retained since they would have had a strong impact on the power consumption of the platform (motors within the camera and need to keep the modem on when driving the camera) and on the amount of data passing through the network (limited by the GPRS subscription). As a result, the camera maintains fixed position, focal length and focus.

It is necessary to regularly retrieve the images that are stored directly on the SD card of the control camera by connecting to the camera from a personal computer (PC) using the Ethernet link from the RIPLE cabinet during the field visits. This allows users to retrieve all the control images for subsequent archiving, because it is possible for some images to be poorly or not at all remotely transferred by the data logger due to the variable quality of the $3 \mathrm{G}$ connection.

\subsubsection{Large-scale particle image velocimetry digital camera}

This camera is dedicated to the large-scale particle image velocimetry (LSPIV) analysis, which is an optical technique 


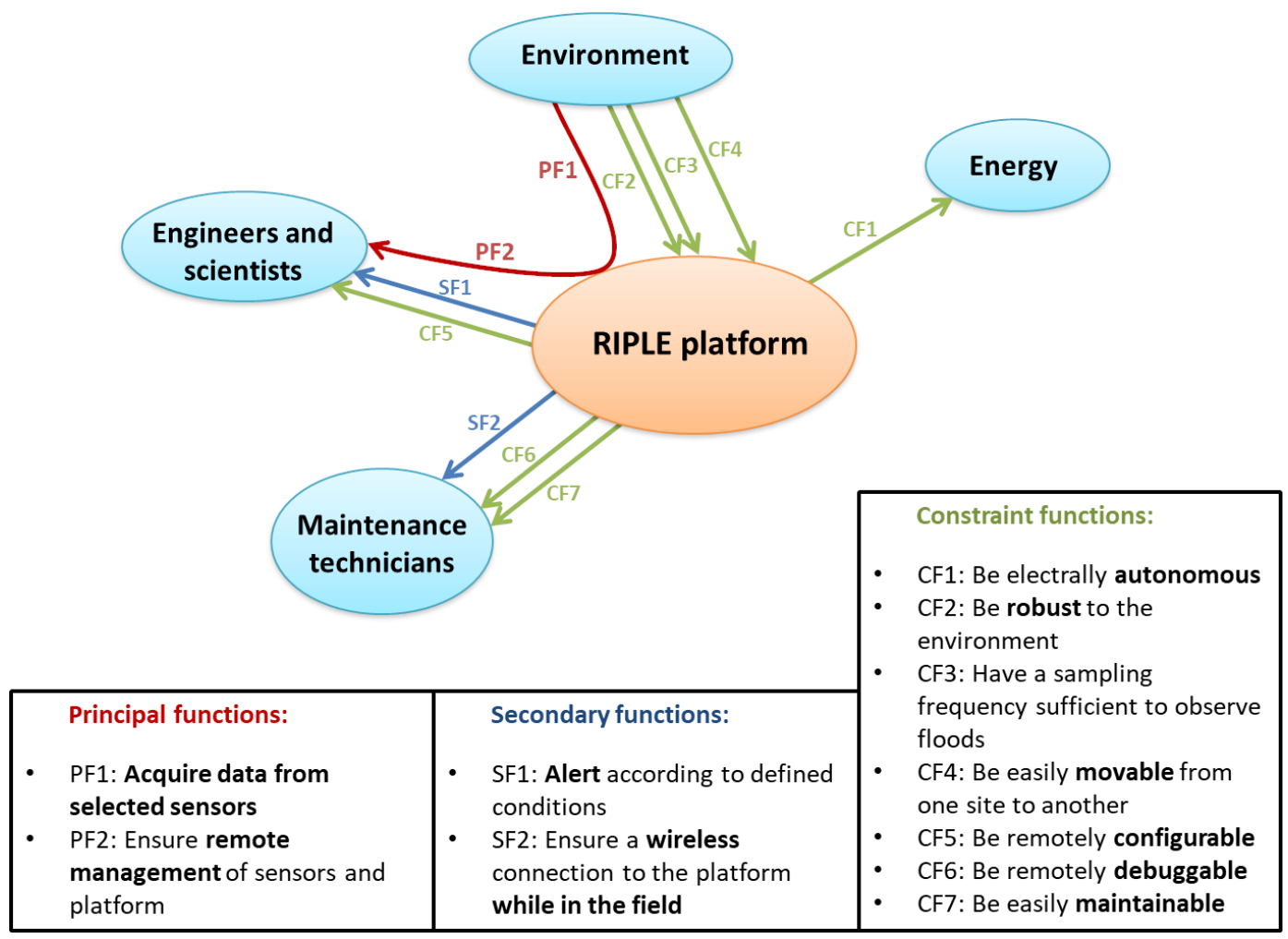

Figure 1. Diagram of the functions to be taken into account for the design of the RIPLE platform.

Table 2. Power balance of instruments integrated into the RIPLE platform.

\begin{tabular}{|c|c|c|c|c|c|c|}
\hline System & $\begin{array}{r}\text { Number of } \\
\text { measurements } \\
\text { per day }\end{array}$ & $\begin{array}{r}\text { Operating } \\
\text { consumption } \\
\left(\mathrm{mAh} \mathrm{d}^{-1}\right)\end{array}$ & $\begin{array}{r}\text { Standby } \\
\text { consumption } \\
\left(\mathrm{mAh} \mathrm{d}^{-1}\right)\end{array}$ & $\begin{array}{r}\text { Integration into current } \\
\text { version of RIPLE } \\
(0: \text { no, } 1: \text { yes })\end{array}$ & $\begin{array}{r}\text { Total daily } \\
\text { consumption } \\
\left(\mathrm{mAh} \mathrm{d}^{-1}\right)\end{array}$ & $\begin{array}{r}\text { Total daily } \\
\text { consumption } \\
\left(\mathrm{Wh} \mathrm{d}^{-1}\right)\end{array}$ \\
\hline Campbell CR6 & - & 1560.0 & 780 & 1 & 2340.0 & 29.5 \\
\hline Module CDMA-108 & - & 240.0 & 187.2 & 1 & 427.2 & 5.4 \\
\hline Modem & 1 & 193.7 & 10 & 1 & 203.7 & 2.6 \\
\hline Water level radar & 144 & 18.0 & 0 & 1 & 18.0 & 0.2 \\
\hline Water velocity radar & 144 & 132.0 & 22.8 & 1 & 154.8 & 2.0 \\
\hline LSPIV camera & 24 & 333.3 & 0 & 1 & 333.3 & 4.2 \\
\hline Control camera & 24 & 333.3 & 0 & 1 & 333.3 & 4.2 \\
\hline IQ Plus & 144 & 300.0 & 48 & 0 & 0.0 & 0.0 \\
\hline Conductivity probe & 144 & 12.0 & 0 & 1 & 12.0 & 0.2 \\
\hline S::CAN & 144 & 840.0 & 108 & 0 & 0.0 & 0.0 \\
\hline Turbidimeter & 144 & 664.0 & 0 & 1 & 664.0 & 8.4 \\
\hline Optic fibre turbidimeter & 144 & 540.0 & 0 & 1 & 540.0 & 6.8 \\
\hline Aquascat & 0 & 100.0 & 1.9 & 0 & 0.0 & 0.0 \\
\hline Water sampler & 0 & 1600.0 & 165.2 & 1 & 1765.2 & 22.2 \\
\hline SCAF & 4 & 666.7 & 0 & 0 & 0.0 & 0.0 \\
\hline Hydrophone & 144 & 400.0 & 86.4 & 1 & 486.4 & 6.1 \\
\hline Echo sounder & 144 & 480.0 & 0 & 1 & 480.0 & 6.0 \\
\hline Total & & 8413.0 & 1409.5 & & 7758 & 97.7 \\
\hline
\end{tabular}




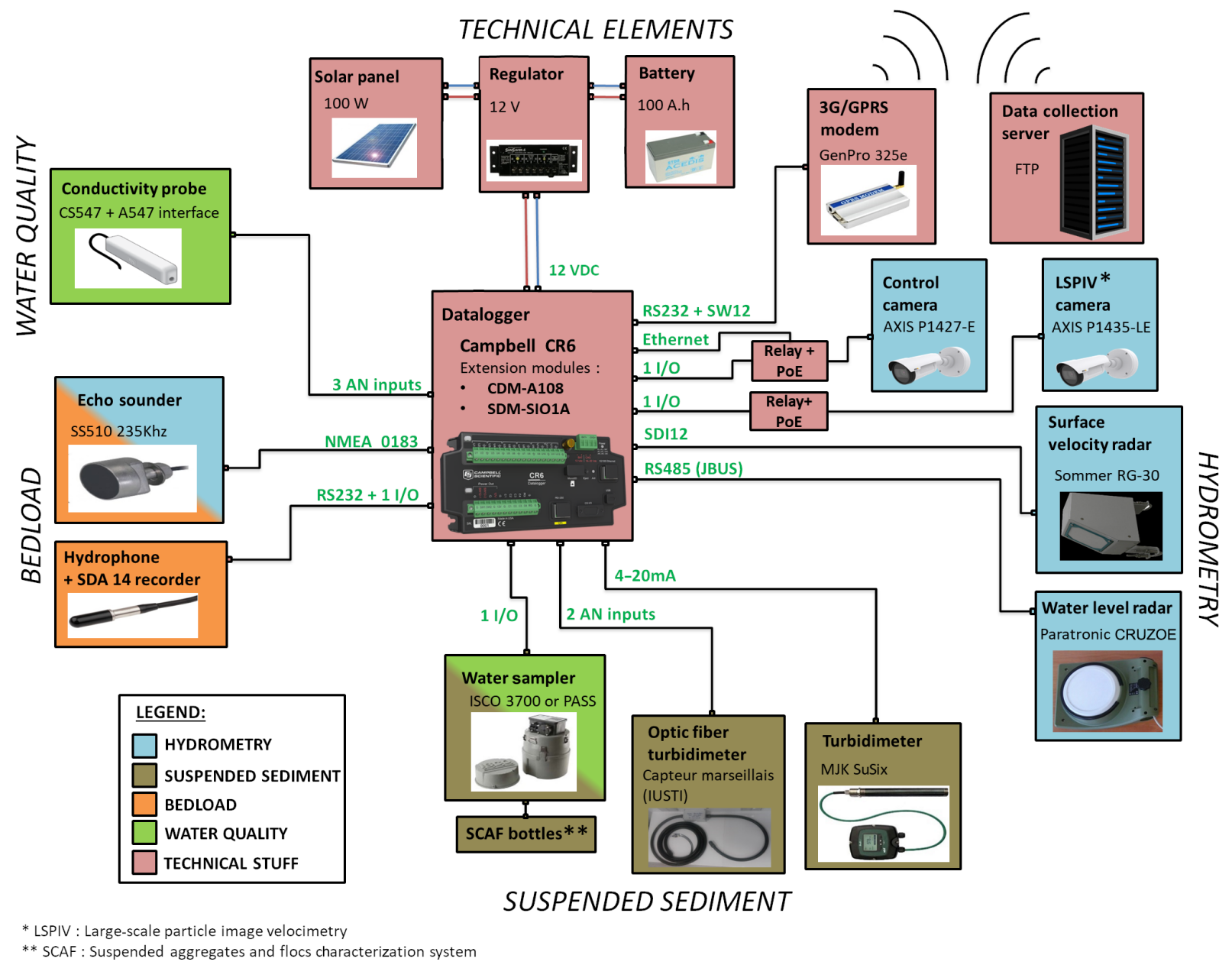

Figure 2. The RIPLE platform architecture.

for measuring surface velocity fields from image processing algorithms, and analysing the movement of natural tracers (leaves, floating branches, turbulent eddies) present on the water surface using a video of the river. A transect of surface velocity along the cross section of the river is extracted and converted to a transect of depth-averaged velocity over the vertical using a coefficient that relates the depthaveraged velocity to the surface velocity. Such a coefficient commonly ranges between 0.75 and 0.85 (Hauet et al., 2008; Le Coz et al., 2010; Welber et al., 2016), but it is preferable to define it from aDcp or impeller or electromagnetic current meter measurements in accordance with ISO 748 and USGS (U.S. Geological Survey) guidelines. Afterwards, knowing the cross section geometry, discharge is calculated by integrating depth-averaged velocities along the cross section with an accuracy of approximately $20 \%$ (Welber et al., 2016).

The major advantages of this technique are the nonintrusive aspect (sensor out of water) and the automation of the acquisition, which allows users to obtain surface velocity fields without any human resources on site. There is no risk for operators and no risk of missing the peaks of the floods, with the exception of night-time and technical problems. In this study, the LSPIV technique is not used to obtain continuous time series of discharge due to the limitations of the method (see below) and our inability to monitor the bathymetry of the section continuously. Alternatively, this technique provides a set of "automatic" discharge measurements that makes the building of a stage-discharge relation easier and faster. The main drawbacks of the technique are as follows: (i) a manual selection of the video sequences is necessary, because some videos are not usable (e.g. lack of brightness, sun reflections, presence of dirt or water drops on the lens); (ii) the LSPIV processing steps are relatively time consuming and require a specific expertise. These steps include a possible correction (depending on the focal length used) of image distortion, orthorectification of images (transformation of the image from fixed objects whose exact GPS location is known) in order to have the same scale at each point of the images, calculation of surface velocity and flow discharge. These steps are performed using the Fudaa-LSPIV software, a free software available on- 
line (https://forge.irstea.fr/projects/fudaa-lspiv/files, last access: 11 March 2020) that uses the Fudaa libraries released under the GPL licence; (iii) the method is not applicable during the night.

The camera is an AXIS P1435-LE. Its selection was based on various criteria such as image resolution, acquisition frequency, zoom and focus, power consumption, robustness to the environment, possibility of recording on SD card, and the presence of an integrated IR projector for tests at nighttime. The camera has an adjustable resolution from $160 \times 90$ to $1920 \times 1080(2 \mathrm{MP})$. Preliminary tests have shown that a minimum resolution of $600 \times 400$ is required for rivers with widths less than $30 \mathrm{~m}$, but the resolution can be increased if needed. Resolution is more important for the precise positioning of the control points than for the visualization of the tracers. There is a link between resolution and focal length to be taken into account. The minimum-to-maximum focal lengths of the zoom lens are $3-22 \mathrm{~mm}$. The aperture is $f / 1.4$ for focal lengths from 3 to $10.5 \mathrm{~mm}$ and $f / 1.85$ for focal lengths from 10 to $22 \mathrm{~mm}$. The horizontal angle of view ranges between 18 and $95^{\circ}$. This wide range of angle of view makes it possible to adapt to many sites. For positioning the camera and adjusting the angle of view, the following conditions must be respected (Le Boursicaud et al., 2016): (i) both river banks have to be visible in the image so that a complete cross section is monitored; (ii) fixed and permanent markers (tree trunk, boulder, bridge pier, etc.) should be present within the images, ideally placed on river banks; (iii) the targeted cross section should be close to the cross section that includes the water level sensor and the staff gauge to have an accurate estimation of the wetted cross section. Furthermore, to optimize the results of the LSPIV technique, it is suitable to focus on an area where surface flow is as regular as possible; users should favour a stretch of river with a hard and stable bottom and avoid as much as possible solar reflections, scintillations and cast shadows. To meet all these criteria, it is preferable to install the camera at a significant height above the river. This will also prevent the use of a low focal length that causes high distortion with this type of lens and is difficult to correct later.

The frame rate is up to 50 or $60 \mathrm{fps}$ (frames per second) in all resolutions. A minimum frame rate of $25 \mathrm{fps}$ is used in this study. It is important that the interval between two images be constant and accurate. The consumption of the camera is $5 \mathrm{~W}$, and it can be turned off while it is not taking videos. The camera is connected to a PoE (Power over Ethernet) injector (see Fig. 2). The PoE injector is connected to the power supply. The data logger controls a relay that supplies power to the PoE injector. In terms of protection against solids and liquids, the enclosure of the camera complies with the Ingress Protection IP66. The camera can operate from -30 to $55^{\circ} \mathrm{C}$ and with a relative humidity between $10 \%$ and $100 \%$ (including condensation). The duration of the video sequences is $10 \mathrm{~s}$. It is a compromise between, on the one hand, the minimum number of image pairs required to make a robust cal- culation and to average turbulent velocities and, on the other hand, the amount of data to be stored. The video sequences can be recorded on an SD memory card. A $10 \mathrm{~s}$ video at a resolution of $2 \mathrm{MP}$ and an acquisition rate of $25 \mathrm{fps}$ without further compression typically generates a $30 \mathrm{MB}$ (megabyte) file. A 64 GB (gigabyte) SD memory card is therefore used in this application. For night measurements, an integrated infrared (IR) projector based on highly efficient light-emitting diodes (LEDs) with adjustable intensity and angle of illumination is available. However, primarily tests have shown that the projector is not powerful enough to illuminate the water surface.

The triggering of the acquisition is programmed as follows: (i) the camera is started by the data logger via the relay for $2 \mathrm{~min}$ at regular intervals (typically every $30 \mathrm{~min}$ ) when triggering conditions of turbidity and water levels are exceeded, i.e. during flood, (ii) the camera takes a short video $(10 \mathrm{~s})$ of the river and records the acquisition directly on its 64 GB SD memory card, and (iii) the camera is switched off via the relay.

The video sequences stored in the LSPIV camera are retrieved regularly during field visits by connecting to the camera from a PC using the Ethernet link from the RIPLE cabinet. The LSPIV processing steps are executed back in the laboratory in Grenoble. It is important not to change the position, angle of view or focus of the camera in order to easily reproduce the LSPIV processing chain. Finally, it was chosen not to use the same camera for the control and for the LSPIV, even though this solution had initially been considered, because the installation constraints specific to each of them are generally very different.

\subsubsection{Surface velocity radar}

The surface velocity radar model RG-30 from Sommer company was selected in this study. It was designed for noncontact measurement of the surface flow velocity of river and channels. The sensor is mounted above the river, usually installed on bridges or river banks using extension arms (Fig. 4). The radar sensor requires a low maintenance operation over many years.

The sensor emits a $24 \mathrm{GHz}$ microwave beam (K-band) towards the water surface inclined by an angle of $58^{\circ}$ from the vertical axis. The radar sensor has an opening angle of $12^{\circ}$; hence, the projected area over the water surface of the river is an ellipse. The measurement of the flow velocity is based on the principle of the Doppler frequency shift. The reflected electromagnetic wave from the water surface is received by the antenna, analysed and converted into surface water velocity. Every measurement is space averaged over the elliptical target area. The size of the targeted area, which depends on the distance from the sensor to the reflecting water surface, increases as water level decreases. The velocities appearing in this area have a specific distribution depending on the flow conditions. The velocity distribution is determined 
with a digital signal processor via spectral analysis and the dominant velocity in the measurement area is calculated (internal processing developed by the Sommer company and not available to the user). Spectra can be output using the RQCommander software (Sommer company) by directly connecting a PC to the RG-30 radar using a serial connection (RS-485). These spectra cannot be sent to the data logger, they can therefore only be used to evaluate the quality of the measurements during visits to the site. The quality of radar velocity measurements depends on flow surface patterns. As the flow surface is exposed to external disturbance, caused by wind or rain, the system measurements become less reliable. Similarly, when no surface patterns are present on the surface, the measurement is biased (Welber et al., 2016). Velocity measurements are possible if the wave height exceeds $3 \mathrm{~mm}$; higher waves improve the reproducibility of the measurement. In the same way, the best measurements are obtained when water is turbid.

The enclosure of the RG-30 complies with the Ingress Protection IP68. It has been designed to withstand exceptional floods with punctual immersion and can operate from -30 to $55^{\circ} \mathrm{C}$. The radar sensor can be mounted in a range from 0.5 to $30 \mathrm{~m}$ above the water surface or riverbed. The radar sensor can either be mounted in or opposite to the flow direction. A view direction against the flow direction is recommended by the manufacturer. The measuring range is from 0.30 to $15 \mathrm{~m} \mathrm{~s}^{-1}$, the accuracy is $\pm 0.02 \mathrm{~m} \mathrm{~s}^{-1}$ and the resolution is $1 \mathrm{~mm} \mathrm{~s}^{-1}$. However, experience shows that the signal can be noisy at low velocity, typically less than $0.5 \mathrm{~m} \mathrm{~s}^{-1}$.

Every $10 \mathrm{~min}$, the measurement is ordered by the data logger using a Serial Data Interface at 1200 baud (SDI12) protocol. Every measurement is time averaged over 30 records obtained in a time interval of $30 \mathrm{~s}$. In addition to the velocity, a quality value of the measurement is provided and recorded. The radar is put on standby by the data logger between each measurement to limit power consumption.

\subsubsection{Water level radar}

The water level radar CRUZOE manufactured by Paratronic was selected in this study. It is designed for non-contact measurement of water levels in rivers or channels. The sensor is mounted above the river, usually installed on bridges or river banks using extension arms (Fig. 4). Flow areas that can be hydraulically disturbed by bridge piers must be avoided. The sensor should preferably be placed in the same section as the staff gauge.

The system emits a short microwave impulse (24.125 GHz, K-band) towards the water surface and captures the reflected signal. The radar sensor has an opening angle of $12^{\circ}$. The radar antenna is both emitting and receiving. The sensor derives the time of flight of the impulse. Accounting for this time of flight and the velocity of the wave in the air, which depends on the air temperature, the radar calculates the distance from the sensor to the water surface. Distances of less than $0.15 \mathrm{~m}$ cannot be measured; this is known as the blind zone.

The radar CRUZOE is easy to use, and it does not require any parameter setting. Indeed, the factory settings allow for its direct use in most cases. It is only necessary to convert the output value into an elevation on the staff gauge, which is the absolute elevation reference of the station. Readings of the staff gauge during field visits or by mean values of the images sent by the control camera allow users to check the validity of the measurement and detect any possible changes in the geometry of the riverbed.

The enclosure of the CRUZOE radar complies with the Ingress Protection IP68. It has been designed to withstand exceptional floods with immersion for $100 \mathrm{~d}$ under $1 \mathrm{~m}$ and can operate from -20 to $60^{\circ} \mathrm{C}$. The radar sensor can be mounted in a range from 0.15 to $30 \mathrm{~m}$ above the water surface or riverbed. The accuracy is $\pm 5 \mathrm{~mm}$ and the resolution is $1 \mathrm{~mm}$.

This radar implements the JBUS protocol on an RS-485 link. MODBUS instructions of the data logger allow communication with this radar. Every $10 \mathrm{~min}$, the measurement is ordered by the data logger. Each logged value is the average of three measuring cycles, each lasting $4 \mathrm{~s}$ and separated by $5 \mathrm{~s}$. During the measurement cycles, the instrument makes 16 measurements per second. In addition, the standard deviation of water level, the ambient air temperature, and three quality indicators of the distance measurement are recorded. The radar is put on standby by the data logger between each measurement to limit power consumption.

\subsubsection{Conductivity and temperature probes}

The Campbell Scientific 547 (CS547) probe with the A547 interface was selected for the measurement of electrical conductivity (EC) and temperature of water. The EC sensor consists of three stainless-steel rings mounted in an epoxy tube. Electrical resistance of the water in the tube is measured by excitation of the centre electrode with positive and negative voltage. Temperature is measured with a thermistor since the EC of a solution is highly dependent on the water temperature. Indeed, as the temperature of a sample increases, the viscosity of the sample decreases, resulting in increased ion mobility. As a result, the observed conductivity of the sample also increases, even if the ion concentration remains constant. To obtain comparable results, the measured values must be reported at a uniform reference temperature (generally $25^{\circ} \mathrm{C}$ ). A simple method of correction of the effect of temperature on the EC measurement is applied assuming a linear relationship between temperature and EC.

The CS547 probe is resistant to water and corrosion. It is also easy to clean. The output signal is an analogical signal $(4-20 \mathrm{~mA})$. The range of measurement for EC is from 0.005 to $7 \mathrm{mS} \mathrm{cm}^{-1}$ and the accuracy is $\pm 10 \%$ of reading for 0.005 to $0.44 \mathrm{mS} \mathrm{cm}^{-1}$ and $\pm 5 \%$ for 0.44 to $7.0 \mathrm{mS} \mathrm{cm}^{-1}$. The 
range of measurement for temperature is from 0 to $50^{\circ} \mathrm{C}$ and the accuracy is $\pm 0.4^{\circ} \mathrm{C}$.

Every $10 \mathrm{~min}$, the measurement is ordered by the data logger. Every measurement is time averaged over 30 records and obtained in a time interval of $30 \mathrm{~s}$. In addition to the average EC and average temperature of water, the min and max values of EC, the standard deviation of EC, and the average value of raw EC (the value with no correction for temperature effect) are recorded.

\subsubsection{Automatic river water samplers}

Two types of automatic river water samplers were selected for this study:

i. the ISCO 3700 manufactured by Teledyne and (ii) the PASS (Huon et al., 2017; M-Tropics, 2017) developed by IRD (Institut de Recherche pour le Développement) for low-cost applications with an adaptable number and volume of sampling bottles. As shown in Fig. 2, automatic water samplers are useful both for measuring SSC and for all subsequent analyses of dissolved and particulate phases, including major ions, nutrients, contaminants, microorganisms and DNA.

ii. The ISCO 3700 portable sampler is commonly used in hydrological, biogeochemical and suspended sediment studies. It can contain 24 wedge-shaped $1 \mathrm{~L}$ polypropylene bottles or 24 cylindrical $350 \mathrm{~mL}$ glass bottles. The ISCO 3700 allows users to perform sequential or composite samples based on time or physical conditions that come from other sensors (e.g. water level, discharge or turbidity). In this study, only sequential samples are taken and the sampling is triggered with external impulses coming from the data logger. The ISCO 3700 features a patented liquid detector. It is equipped with a peristaltic pump which delivers accurate and repeatable sample volumes time after time. The system includes an automatic compensation for changes in head heights and an automatic suction-line rinsing to eliminate sample cross-contamination. The pump maintains a suction velocity of $0.66 \mathrm{~m} \mathrm{~s}^{-1}$ recommended by ISO standard 5667-10 up to $4.5 \mathrm{~m}$ of vertical drop. The suction strainer is generally located relatively low in the river depth to sample any type of flood and any type of suspended particle.

In the case of exceeding turbidity and water level thresholds, the values of which depend on the site and the season, the data logger will send an impulse to the sampler which will initiate the sampling of a river water sample. If both turbidity and water level thresholds continue to be exceeded, and if a time interval is reached since the last sampling, the next sample will be collected. The time interval between two samplings depends mainly on the site and the season.
The PASS sampler is a more flexible alternative than the ISCO in terms of the number and shape of its containers. Any container in plastic, glass or other material with a top opening can be used. This system is controlled by the Campbell CR200 data logger that controls a pump and four stepper motors (two in $x$ direction and two in $y$ direction). This system was completely developed and tested in the M-TROPICS Critical Zone Observatory in Laos (Ribolzi et al., 2017). In this study, the same pump as the ISCO 3700 portable sampler was tested.

\subsubsection{Turbidimeters}

Two types of turbidimeters were selected for this study: (i) a standard instrument manufactured by MJK (the SuSix sensor) for turbidity ranging from 0.001 to 9999 FNU/NTU (FNU: Formazin Nephelometric Unit, NTU: Nephelometric Turbidity Unit) (equivalent to suspended solids ranging from 0.001 to $400 \mathrm{~g} \mathrm{~L}^{-1}$ of $\mathrm{SiO}_{2}$ according to the manufacturer) and (ii) a turbidimeter developed by IUSTI (Institut Universitaire des Systèmes Thermiques Industriels) for the specific case of rivers with very high SSC (up to several hundreds of grams per litre of SSC).

i. The SuSix sensor uses a multi-beam pulsed-infraredlight system (wavelength of $860 \mathrm{~nm}$ ). The beamforming optics for multi-angle detection combined with a progressive algorithm using neural logic constitute a reliable high-quality measurement of turbidity in a single sensor according to the manufacturer. The turbidity measurement complies with ISO standard 7027. The SuSix sensor is equipped with a wiper to remove mineral and organic deposits from the optical cells. A SuSix converter without display (10-30 V DC) on which certain parameters can be adjusted (unit, measuring range) is needed between the SuSix sensor and the data logger. The standard RS-485 connector is used for the serial communication between the sensor and the converter with a proprietary protocol. An additional display unit for SuSix is installed and connected exceptionally for the configuration of the system and the sensor. During normal operation, the converter without display allows for the most economical use possible in terms of power consumption. The converter outputs a 4-20 mA signal to the data logger. The setting of the 4-20 mA output range depends on the turbidity range. In the case of a river with high SSC, the following values are used: $4 \mathrm{~mA}=0 \mathrm{FNU}, 20 \mathrm{~mA}=9999 \mathrm{FNU}$. The SuSix sensor is constructed of stainless steel with a chromium dioxide coating and scratch-resistant sapphire lenses in a highly polished stainless-steel sensor face. The accuracy is $\pm 0.1 \%$ of reading.

The converter is started by the data logger via the relay every $10 \mathrm{~min}$. Every measurement lasts for $30 \mathrm{~s}$ and records 30 values. In addition to the average turbidity, 
the min and max values of turbidity, the standard deviation of turbidity, and raw value of turbidity in millivolts are recorded. Finally, the converter is switched off via the relay. The wiper for cleaning the sensor is activated when a $12 \mathrm{~V}$ pulse is received, generated once a day by the data logger.

ii. The turbidimeter developed by IUSTI, the so-called capteur marseillais, is a sensor made up of a bundle of optical fibres. This sensor which was initially designed for the Draix-Bléone Observatory has shown great robustness, operating on site without maintenance since July 1994. Four sensors and their electronics are still in operation today. The operating principle of the capteur marseillais is described in detail by Bergougnoux (1995), Bergougnoux et al. (1998) and Bellino et al. (2001). The sensor head is made of optical fibres with a diameter of $750 \mu \mathrm{m}$. There is an emitting fibre in the centre surrounded by two rings of receiving fibres. The first layer contains 6 receiving fibres; the second layer contains 12 receiving fibres. The sensor consists of a stainless steel head that is to be immersed in the river, a flexible black polyamide sheath to guarantee good mechanical protection of the optical fibres, a waterproof housing containing the LED and the two photodiodes to which the two families of receiving fibres are connected. An electronic box connected to the fibre optic sensor by three BNC connectors of $5 \mathrm{~m}$ cable allows for the amplification of the signals delivered by the two families of receiving fibres. This electronic box, powered by a 0 $12 \mathrm{~V} \mathrm{DC}$ supply, is equipped with two analogue outputs in voltage between 0 and $5 \mathrm{~V}$, compatible with the acquisition system. These devices are located in the main electronics box of the platform (Fig. 3). The gains applied to $0-5 \mathrm{~V}$ analogue outputs must be adjusted in relation to the expected turbidity range. The ratio between the signals of the two receiver fibre layers gives a proxy of the turbidity. The accuracy of the turbidity measurement depends on the absorption capacity of the particles; it is about $3 \%$ for suspended sediment concentration (SSC) between $1 \%$ and $40 \%$ in volume. This sensor is limited to the measurement of high turbidity values. In addition, it does not have a cleaning system (e.g. wiper or ultrasonic system). It was therefore decided to install it at a higher position than the SuSix sensor so that it is immersed for a shorter period of time than the SuSix sensor, i.e. generally only during the central part of the floods (around the peak of the flood).

Every $10 \mathrm{~min}$, the data logger starts up the power supply of the capteur marseillais via the relay. Every measurement lasts for $30 \mathrm{~s}$ and records 30 values. The recorded measurements are the average and standard deviation of the output voltage of each receiver fibre layer as well as the average and standard deviation of the logarithm of
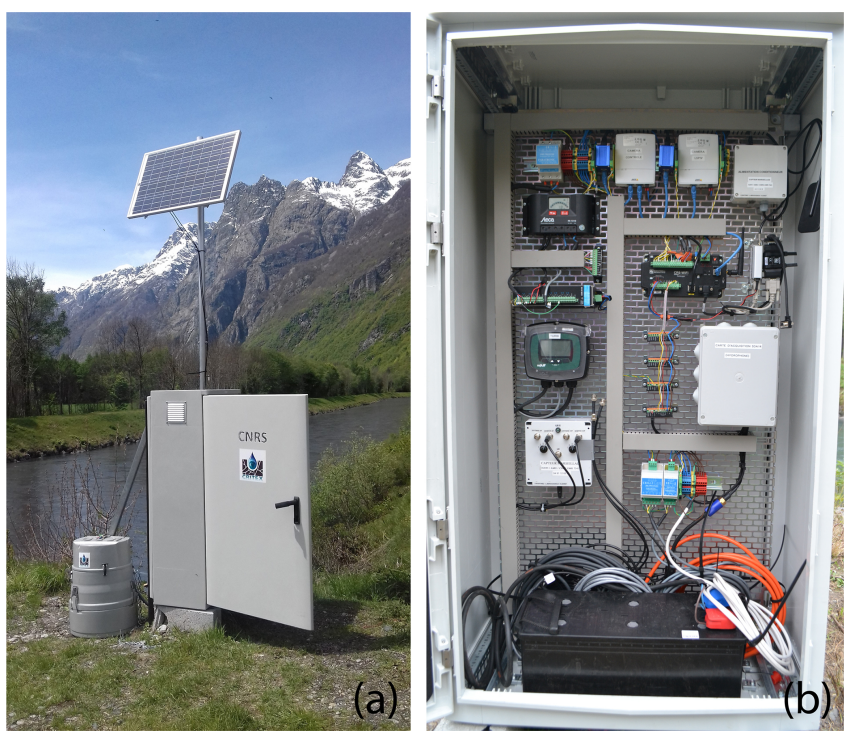

Figure 3. Photos of the box that houses all the electronics of the platform and the battery: (a) outside view where we also see the solar panel and the ISCO automatic river water sampler and (b) inside view.

the ratio between the signals of the two receiver fibre layers.

\subsubsection{System characterizing aggregates and flocs}

The system characterizing aggregates and flocs (SCAF) is an optical settling column composed of a series of 16 infrared emitters/receivers regularly spaced every centimetre (Wendling et al., 2015). The device enables users to measure the temporal evolution of the vertical profile of optical absorbance during the quiescent settling of a suspension, immediately after its sampling from the river. From the slopes of multiple iso-absorbance lines, settling velocity distributions (SVDs) of suspended sediment can be calculated, as well as an indicator of the propensity of particles to flocculate (Wendling et al., 2015). The SCAF is able to operate for a wide range of SSC (from $1 \mathrm{~g} \mathrm{~L}^{-1}$ to several tens of grams per litre) and settling regimes (free, flocculated and hindered settling regimes) as illustrated in Legout et al. (2018). The data produced by the SCAF are useful for the understanding and the modelling of the suspended sediment transport in rivers.

Each unit instrument was designed to be incorporated into sequential samplers. The SCAF was adapted to fit into typical $1 \mathrm{~L}$ wedge-shaped polypropylene bottles used for ISCO 3700 automatic samplers. A round bottle in glass $(0.20 \mathrm{~m}$ high and $0.035 \mathrm{~m}$ in diameter) receiving the suspension sampled from the river $(170 \mathrm{~mL})$ and the associated memory card is housed inside the $1 \mathrm{~L}$ wedge-shaped polypropylene bottle. The optical system is composed of 16 infrared $(\lambda=980 \mathrm{~nm})$ emitters and 16 diametrically opposed photosensors measuring at 

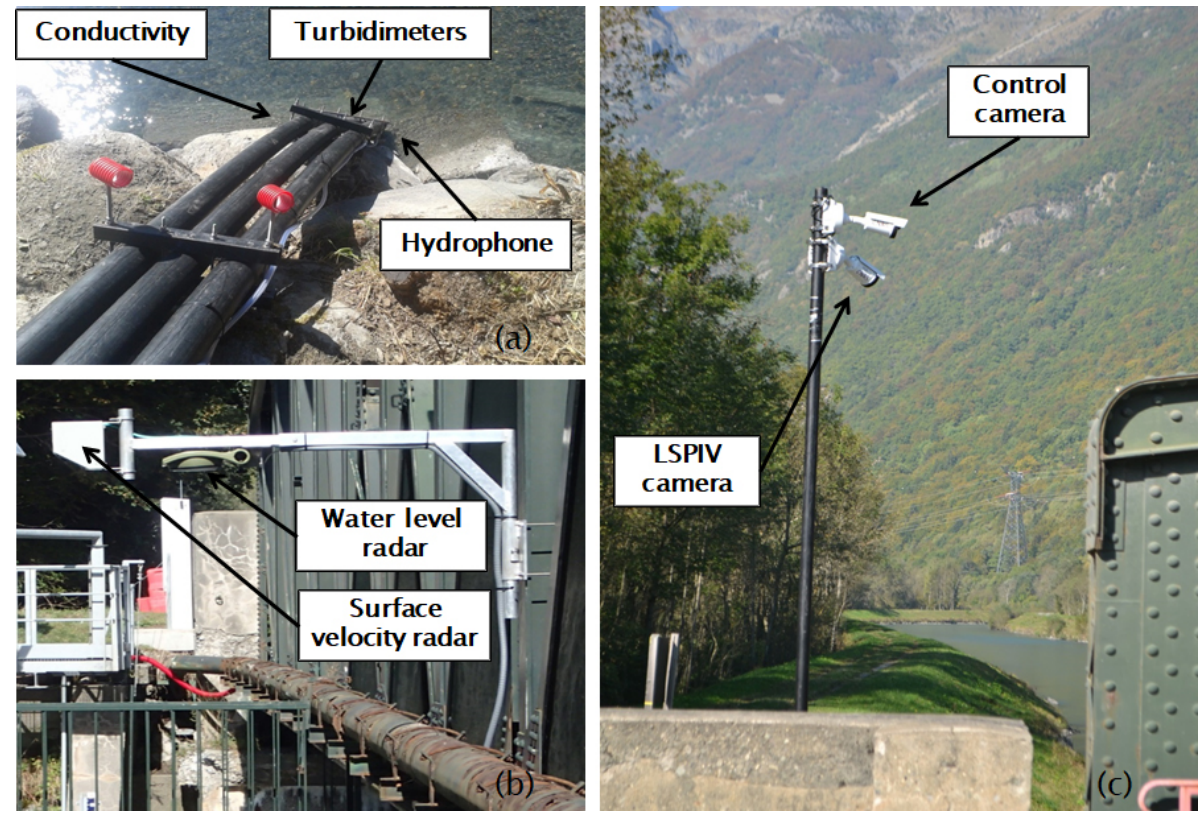

Figure 4. Photos illustrating the deployment of instruments in situ (a) submerged instruments (conductivity probe, turbidimeters and hydrophone) housed in the polypropylene tubes anchored to the river bank; (b) water level and surface velocity radars supported by extensible brackets fixed to the bridge parapet; (c) control digital camera and LSPIV digital camera fixed at the top of a mast located on the river bank.

a frequency of $210 \mathrm{~Hz}$. Currently, up to eight units can be placed in a ISCO 3700 sampler dedicated to the SCAF device.

The SCAF measurements begin after a delay of $20 \mathrm{~s}$ following the impulses emitted by the data logger to the ISCO. The delay corresponds to the time of purge and pumping of the $170 \mathrm{~mL}$ of the suspension by the ISCO sampler. Measurements are acquired every $100 \mathrm{~ms}$, each value being the average of 10 measurements. The SCAF measurements typically last over $5 \mathrm{~h}$ as shown in Legout et al. (2018). Each SCAF unit is working separately, waiting for the various impulse sequences of the data logger.

\subsubsection{Echo sounder}

The echo sounder Airmar SS510 was selected to be integrated into the RIPLE platform. It allows users to perform a continuous measurement of the distance to the riverbed at one point of the cross section. As a result, changes in the geometry of the cross section related to erosion/deposition of sediment or bedload transport can be detected at high temporal resolution, especially during flood events when geomorphic processes may occur. As shown in Fig. 2, the echo sounder provides information on the bathymetry of the cross section that is useful for both bedload and hydrometry. The Airmar SS510 sensor, featuring embedded micro-electronics, processes depth and temperature signals inside the sensor and transmits data via two separate communication protocols. The first is a bidirectional interface compliant with the NMEA-0183 protocol, and the second is a transmit-only in- terface with a proprietary protocol using RS-485, which is used in this study. The acoustic frequency used by the sensor is $235 \mathrm{kHz}$. The power output from the transmitter is $100 \mathrm{~W}$. There are minimal side lobes for concentrated energy on target. The beam width is $8^{\circ}$, and the range of depth is between 0.4 and $200 \mathrm{~m}$ with an accuracy of $\pm 0.03 \mathrm{~m}$ for applications in mesoscale rivers (depth typically lower than $5 \mathrm{~m}$ ) with the sensor tilt with angles of less than $25^{\circ}$ from the vertical axis. The accuracy of the temperature sensor is $\pm 0.05^{\circ} \mathrm{C}$. The operating temperature ranges from -5 to $60^{\circ} \mathrm{C}$. The sensor is robust with a stainless-steel housing and an acoustic window in urethane. The cylindrical shape and the relatively small size (diameter of $0.07 \mathrm{~m}$ ) of the sensor offers flexibility in the type of mounting. An adjustable attachment piece was designed in this study to fix the echo sounder from a river bank or bridge pier. The mechanical integration of the echo sounder into the river is the main problem associated with this instrument as it is potentially exposed to bedload transport, and there is not always a hard point available to fix it.

Every $10 \mathrm{~min}$, the measurement is ordered by the data logger via a RS-422 serial communication. By default, the echo sounder returns the measured depth and water temperature every second. Every measurement is time averaged over 30 records. The recorded measurements are the average, min, max and standard deviation of depth as well as the average, min, max and standard deviation of water temperature.

Additionally, the RS-485 interface available on the echo sounder allows users to retrieve detailed information on each measurement made by the echo sounder. To do this, it is 


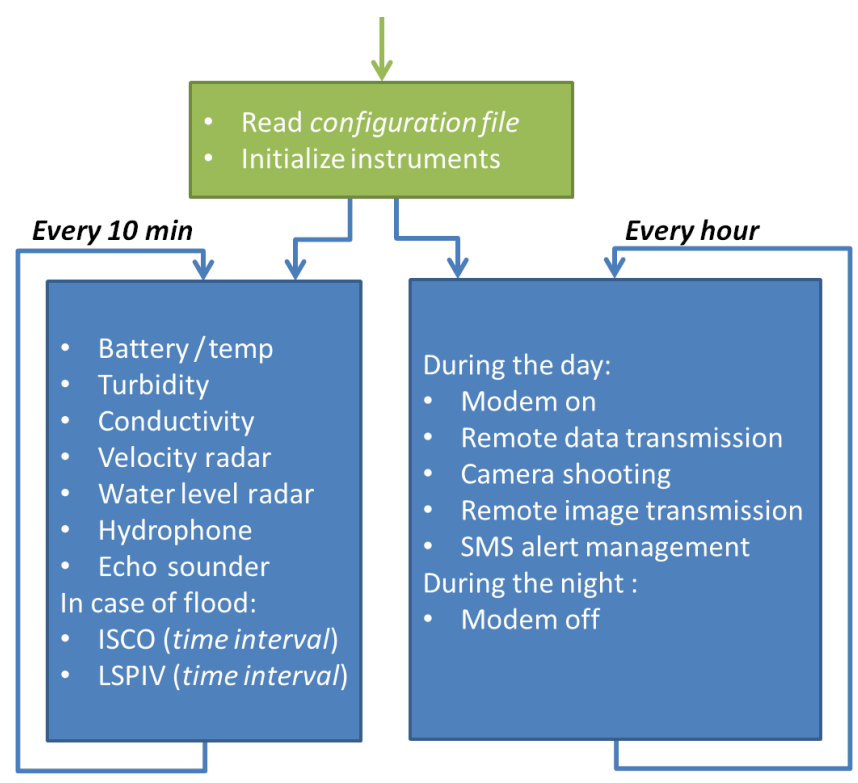

Figure 5. Architecture of the main program that controls the RIPLE platform.

necessary to establish a connection from a PC to the echo sounder with a converter from FTDI (Future Technology Devices International) USB to RS-485 and open a 921600 baud terminal to display these data.

\subsubsection{Hydrophone}

The deployment of hydrophones in the watercourse allows for a continuous monitoring of the sounds naturally generated by bedload transport in the river (Marineau et al., 2016; Geay et al., 2017a). The hydrophone Colmar GP0190 interfaced with the SDA14 acoustic data recorder was selected in this study. The Colmar GP0190 is a pre-amplified omnidirectional hydrophone, for application up to $170 \mathrm{kHz}$ (working band: 5-170000 Hz). The hydrophone can work up to $1000 \mathrm{~m}$ depth. The body of the instrument is in stainless steel. The SDA14 acoustic data recorder was designed by the RTsys company for the acquisition of acoustic signals from passive or pre-amplified hydrophones. It integrates four analogue receivers, allowing for recording of four sound sources simultaneously. Its broadband analogue inputs allow for a frequency of over $500 \mathrm{kHz}$ (from $3 \mathrm{~Hz}$ to over $500 \mathrm{kHz}$ ) with a dynamic range greater than $100 \mathrm{~dB}$, guaranteeing an efficient signal-to-noise ratio. The embedded digital signal processor allows for high-speed acquisition, filtering, storage and preprocessing of the acoustic data. Its power consumption is between $600 \mathrm{~mW}$ to $2 \mathrm{~W}$ in active mode (i.e. during measurements) and less than $1 \mathrm{~mW}$ in sleep mode. The system is designed to operate in stand-alone mode or towed mode. The stand-alone mode is used in this study. Configuration of the SDA14 acoustic data recorder is possible by connecting a PC via Ethernet and using a web interface.
The SDA14 is controlled by the data logger via an RS-232 link and a $0-5 \mathrm{~V}$ output. The triggering of the acquisition is programmed as follows: (i) the data logger sends a $5 \mathrm{~V}$ pulse to wake up the SDA14; (ii) the SDA14 starts and automatically launches an acquisition (manual mode): a record of $30 \mathrm{~s}$ at $156 \mathrm{kHz}$ and with a 24-bit resolution is performed. For information, the parameters of duration, frequency and resolution of the acquisition can be modified in the data logger acquisition program; (iii) data are stored in files with a ".wav" format; (iv) a fast Fourier transform algorithm is operated by the SDA14 to compute the acoustic root-mean-square power in one-third octave bands; (v) the SDA14 transmits integrative spectrum data (RMS power in one-third octave bands, about 20 points of the spectrum) to the data logger via an RS232 link, so useful information on the operation of the hydrophone can then be tele-transmitted to the manager of the platform (it would not be possible to tele-transmit the ".wav" files by GPRS or $3 \mathrm{G}$ as they are too large, i.e. $10 \mathrm{MB}$ for $30 \mathrm{~s}$ of recording); and (vi) the data logger puts the SDA14 in standby via the RS-232 link.

Concerning step (iii) on data storage, the SDA14 is equipped with a 128 GB SD memory card and a 2 TB (terabyte) hard disc drive (HDD) (ext4 format). In order to limit the number of on/off times of the HDD (which would severely limit its lifetime), acquisitions are first recorded on an SD memory card and once it is full, the HDD is turned on to empty the SD card. This is called the "hybrid" mode. There is an RS-232 command returning the available memory in the SD card and in the HDD. The data logger will send an alert when the hard disc is almost full. The SDA14, the SD memory card and the HDD are located in the main electronics box of the platform. The transfer time from the 2 TB HDD to a PC would be far too long to be done in the field. A second HDD was therefore purchased to allow rotations to be done: when a disk is almost full (the state of the storage of the HDD is visible in the RIPLE interface), it is simply replaced by the second HDD previously emptied, and the transfer of the full HDD can be done in the laboratory.

The hydrophone is housed in a polyethylene tube next to the other immersed instruments (turbidimeter, conductivity and temperature probes), which are not switched on during hydrophone acquisitions.

\subsection{Remote data transmission}

The 2G/3G modem Erco\&Gener GenPro 325e was selected in this study as it allows the data logger to upload data and images to the FTP server of the laboratory in Grenoble and also to send alert SMS (text) messages. $2 \mathrm{G}$ antennas are no longer maintained by access providers in France, so we opted for a modem that can use $3 \mathrm{G}$ to remotely transmit data. A SIM (subscriber identity module) card linked to an M2M (machine-to-machine) subscription is inserted into the modem to ensure its operation. 


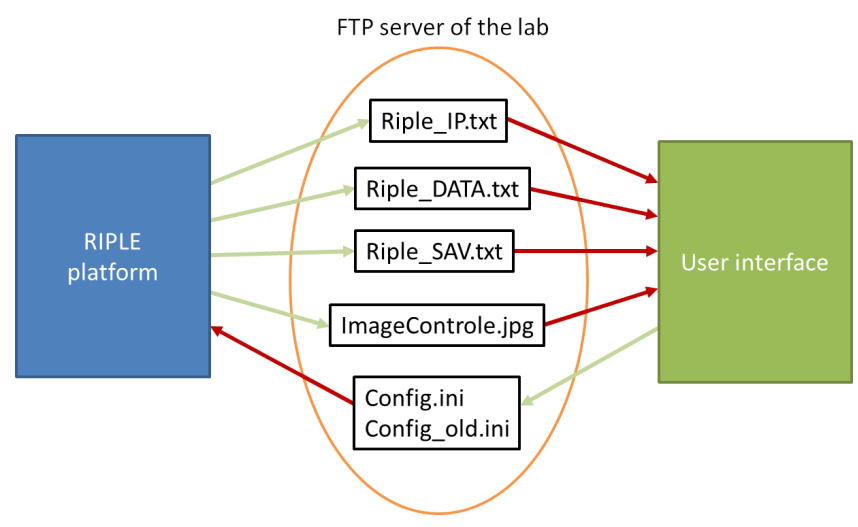

Figure 6. Diagram describing the links between the RIPLE platform, the remote server and the user interface. The "Riple_IP.txt" file contains the current IP address (Internet Protocol, public and dynamic) of the RIPLE platform. The "Riple_DATA.txt" file contains the data from each instrument of the RIPLE platform. The "Riple_SAV.txt" file contains the data that enable users to remotely control the proper functioning of the RIPLE platform. "Config.ini" is the configuration file of the platform, which is generated when the user wants to change the configuration of the platform from a remote location using the RIPLE interface (Sect. 5). A backup of the old configuration is made in the "Config_old.ini" file. "imageControle_Date.jpg" is the image file that the data logger puts on the FTP server. A copy of the image is saved locally on the camera in order to make a reliable archiving of the images (in case of malfunction of the remote transmission for example).

The solution of a private IP address was selected in this study. By making this choice, we accept the dependence on the LoggerNet software of Campbell Scientific, which makes it easy to manage the data logger and set up automatic collections of data. Having a private IP address avoids the possibility of being hacked by a "robot" circulating on the net, which could cause a very significant increase in expenses related to the GPRS subscription. In France, Internet service providers only provide dynamic IP addresses. The LoggerNet software was configured to establish a connection with a station whose address is dynamic by accepting the possibility of temporarily losing the connection because of a change in IP address.

All procedures for the data collection and data transfer to the remote FTP server are presented in Fig. 7. The modem queries the Internet service provider to obtain a private IP address. The data logger is then connected to the $2 \mathrm{G} / 3 \mathrm{G}$ network. The data logger contacts the LoggerNet server via port 6786 . The LoggerNet software running on the LoggerNet server recognizes the data logger with its PakBus number (225 for RIPLE), the connection between the data logger and the LoggerNet server is then established. It is then possible for the manager of the platform to communicate remotely with the data logger. The LoggerNet software can manage different stations; the distinction between different data loggers is made by a unique internal Pakbus address assigned to each station and not by IP address or domain name. In the case of a change of IP address, a connection failure occurs until the data logger automatically sends the next tag to the LoggerNet server and can communicate once again with it. The IP address is changed on average every $24 \mathrm{~h}$ and also when the modem starts up. It is unlikely that the change of IP address occurs within a few hours after the modem is started. As long as the connection is established, the data logger sends its data tables and control images to the FTP server of the laboratory using FTPClient instructions.

The advantages of the selected solution are (i) the possibility to use a classic GPRS modem (low energy consumption and low cost), (ii) the management of data flow in case of transmission errors, and (iii) the possibility to have a twoway communication link.

The shortcomings are (i) the dependency to the LoggerNet package proposed by Cambpell Scientific and (ii) the likelihood to temporarily lose the connection if the IP address is changed.

The CR6 turns the modem on during the day and off at night to limit the power consumption of the platform. Therefore, no data or alerts can be transmitted during the night.

\subsection{Housing}

The RIPLE platform is organized in several parts: (i) the control block, (ii) submerged instruments and (iii) non-intrusive instruments.

i. The control system (CR6, CDM-A108, 4 SDMSIO1A), the power supply (battery, solar regulator, four relays, two PoE injectors), the instrument electronics boxes (SuSix turbidimeter interface, power supply of the capteur marseillais, A547 interface of the conductivity probe, SDA14 card of the hydrophone) and the remote transmission module (modem, antenna) are grouped in an electrical box (dimensions $H=1.40 \mathrm{~m}$, $L=0.80 \mathrm{~m}, D=0.46 \mathrm{~m}$ ) located on the river bank at a height sufficient to avoid being flooded (Fig. 3). Everything is grouped into a single element to facilitate the installation and relocation of RIPLE to other sites. In addition, the ISCO automatic sampler is placed next to the electrical box and the solar panel is fixed on a mast or against the structure of a bridge.

ii. Three main submerged instruments (conductivity probe, SuSix turbidimeter, hydrophone) are housed in polypropylene tubes, $3 \mathrm{~m}$ long and $0.10 \mathrm{~m}$ in diameter, fixed to the bank of the river, parallel to each other. These tubes are clamped between metal profiles at three points (top, middle and bottom of the tubes). The metal profiles are themselves anchored in the bank of the river (bedrock or large blocks) using threaded rods. The three polypropylene tubes are perpendicular to the direction of the flow in the river (see Fig. 4). The instruments are installed within the tubes using PVC pieces of the inner 


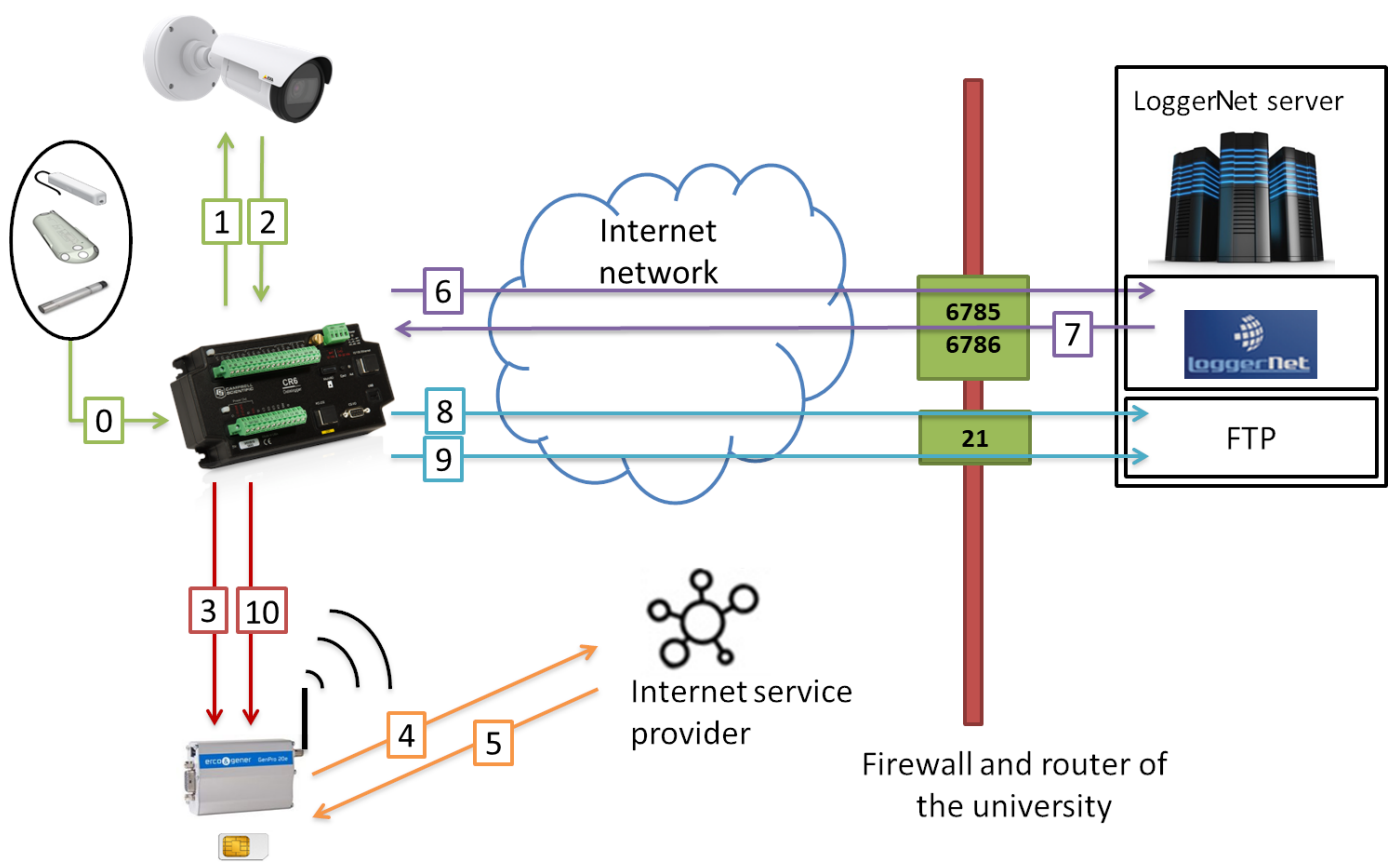

Figure 7. Diagram of the data collection and data transfer to the remote FTP server. (0) The data logger continuously retrieves data from the instruments integrated into RIPLE and stores the results in a table. (1) The data logger supplies power to the control camera for a few minutes, which automatically takes an image when it starts up. (2) The camera, configured as an FTP client, places the image on the data logger, which includes an FTP server. (3) The data logger supplies power to the GPRS modem. (4) The modem queries the Internet service provider to obtain a private IP address. (5) The data logger is then connected to the $2.5 \mathrm{G}, 3 \mathrm{G}$ or $4 \mathrm{G}$ network. (6) The data logger contacts the LoggerNet server via port 6786. (7) The LoggerNet software running on the LoggerNet server recognizes the data logger with its PakBus number and the connection is established. It is now possible for the manager of the platform to communicate remotely with the data logger. (8) The data logger sends its data tables to the FTP server of the laboratory (FTPClient instruction). (9) The data logger transmits the control image to the FTP server of the laboratory (FTPClient instruction). (10) The data logger switches off the modem after a few hours. (11) A web page created under Shiny (R package) is updated after each new data transmission.

diameter of the tubes that are machined to allow the sensors to be inserted. These PVC pieces, connected to the top of the pipes by $4 \mathrm{~mm}$ diameter threaded rods, prevent the movement of the sensors inside the pipes, allow the sensors to be easily removed without human intervention in the river and allow users to put the sensors back to the same location. The lower end of the tubes is at a level low enough to ensure that the instruments are submerged during low-water periods.

In addition, the capteur marseillais, which is composed of a waterproof box including the LED source, photodiodes and a $1.5 \mathrm{~m}$ long sheath with the optical fibres, is fixed to the outside of the polypropylene tubes using cable ties. The dimensions of the box and the length of the optical fibres mean that this instrument cannot be housed inside the polypropylene tubes and the optical fibre heads cannot be lowered to the lower end of the tubes. The measurement is made at a higher level in the water column than the SuSix turbidimeter. The flexible plastic tube that allows ISCO to collect water and suspended sediment from the river is also attached to the polypropylene tubes using cable ties. The end of the flexible tube is positioned very close to the SuSix turbidimeter, at the same level in order to have a maximum correspondence between the two measurements. The other submerged instrument that is not installed within the polypropylene tubes is the echo sounder. This one has a specific support that has been designed to be fixed to a vertical wall (bridge pier for example) by adjusting the angle of orientation of the instrument with respect to the vertical. Finally, a staff gauge is installed in the cross section near the water level radar.

iii. The four non-intrusive instruments used for hydrometric purposes are fixed on masts for both cameras (control, LSPIV) and on extendible mounting brackets for both radars (water level, water surface velocity) as shown in Fig. 4. The brackets are easily movable to facilitate radar maintenance. These devices (masts or mounting brackets) are attached to the structure of a bridge for example. The velocity radar should preferably be placed in the centre of the cross section in the zone of highest velocities. The cameras must be located on the banks at a level high enough to see the full width of the river and part of the banks. 


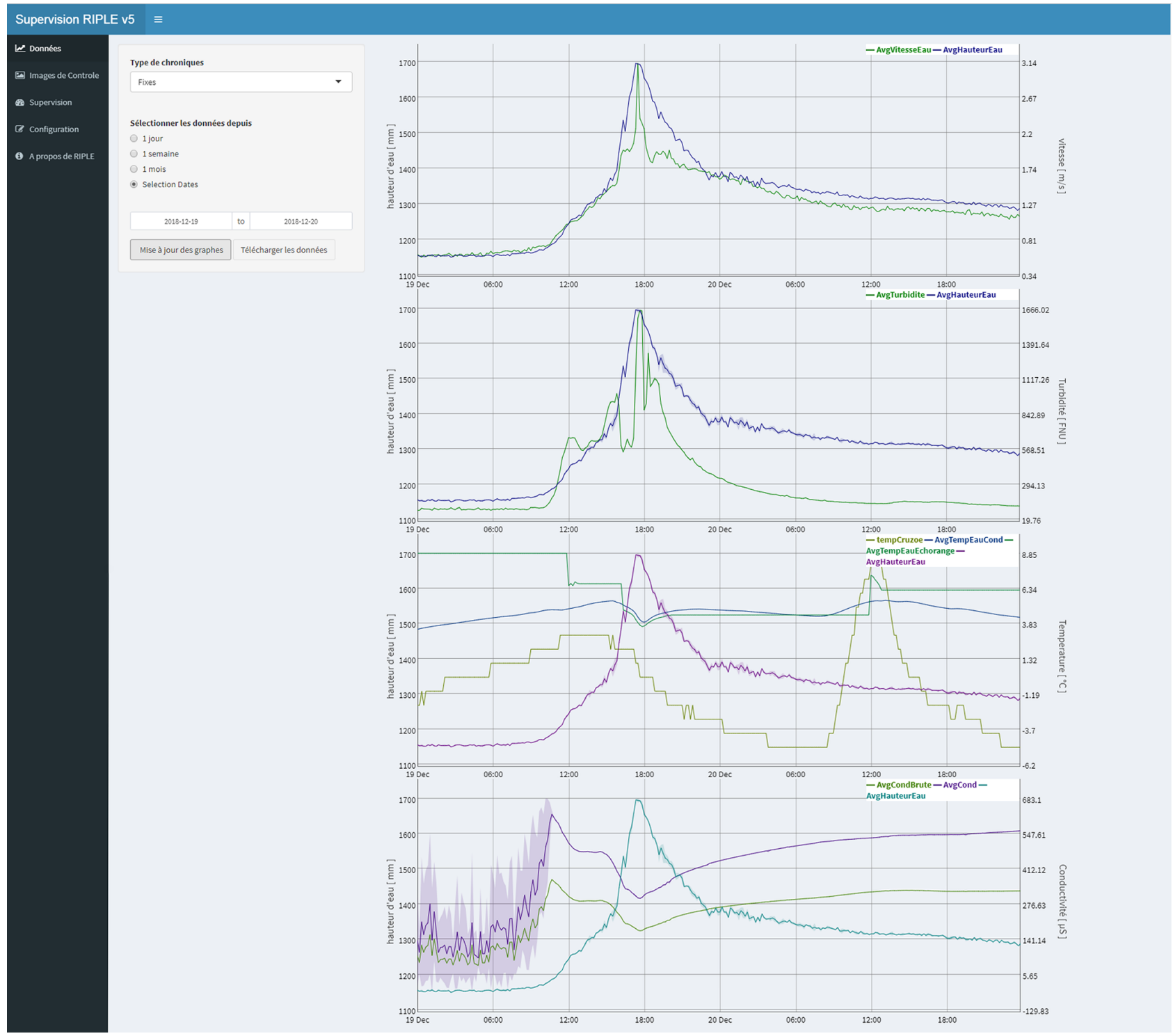

Figure 8. Screenshot of the "Data visualization" menu of the user interface in the default mode. Four time series graphs are displayed from top to bottom: (1) water level and surface water velocity, (2) water level and turbidity, (3) water level and temperature, and (4) water level and conductivity.

\section{Control software}

The data logger controlling program is written in the CRBasic programming language, which is the proprietary format of Campbell Scientific. As shown in Fig. 5, there is a main program that reads a configuration file, initializes the instruments and controls two families of sub-programs: those which are active every $10 \mathrm{~min}$ or every hour.

The sub-programs that are active every $10 \mathrm{~min}$ control all instruments except the control camera. When the water level and turbidity conditions are exceeded and the time since the last sample exceeds a certain interval set by the user, the first automatic sampler is launched. A SCAF measurement is also started, preferably using a second automatic sampler dedicated exclusively to SCAF measurements. Similarly, when a water level condition is exceeded and the time since the last video shot exceeds a certain interval set by the user, the LSPIV camera records a video sequence. The other subprograms that are called at an hourly frequency are only active during daytime. This concerns the operation of the modem, image capture by the control camera, image and data transmission, and SMS message sending in case of alerts (low battery voltage, full ISCO sampler, etc.).

The RIPLE platform is interfaced with the rest of the world via the FTP server, which allows for exchanges between the interface (see Sect. 5) and the platform as shown in Fig. 6. 


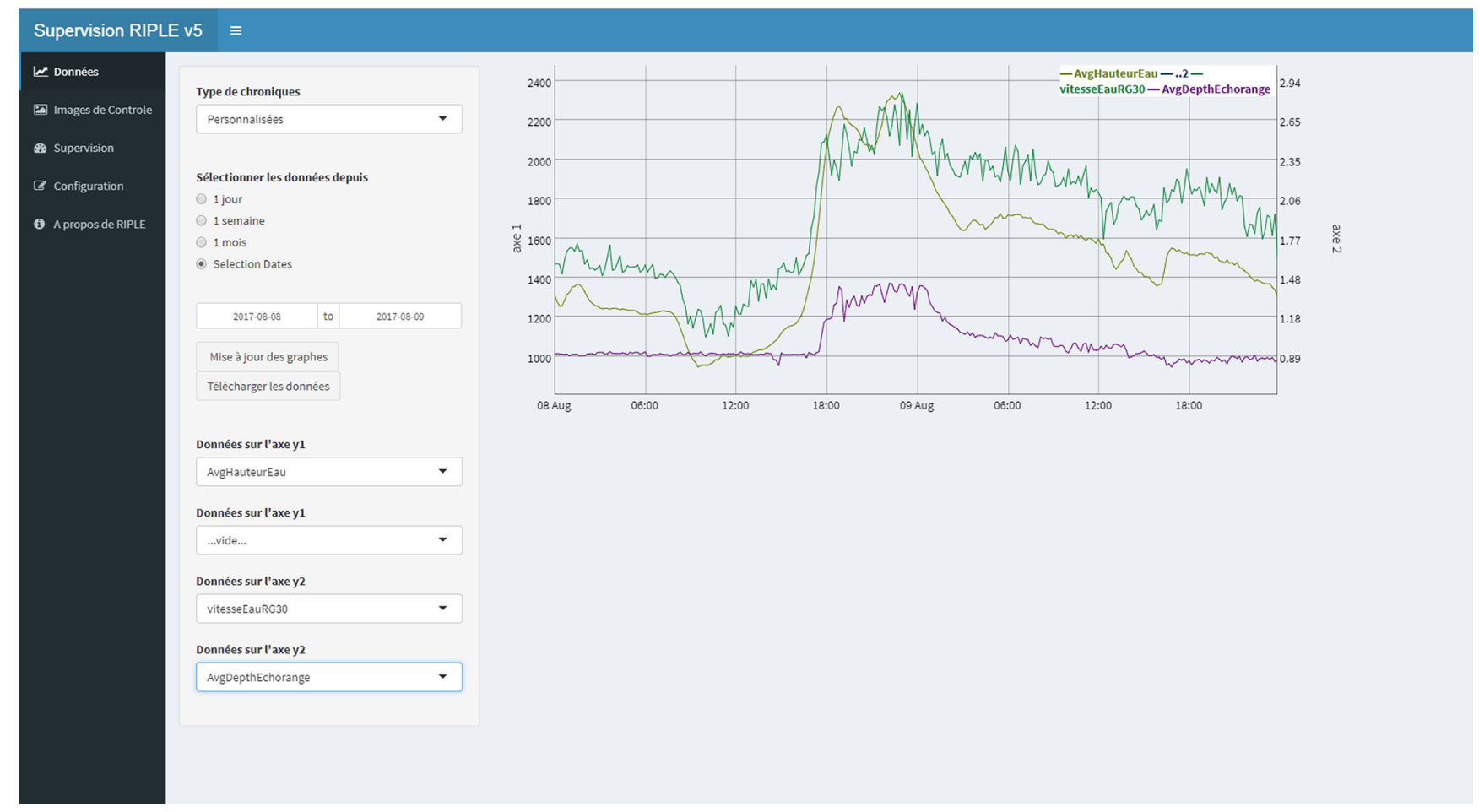

Figure 9. Screenshot of the "Data visualization" menu of the user interface in the personalized mode. A graph can be created with two variables on the first $y$ axis and two variables on the second $y$ axis, with time on the $x$ axis. In this case, the water level, water surface velocity and distance measured by the echo sounder are displayed.

The procedure for the operation of data storage and transfer can be illustrated by Fig. 7 .

Concerning specifically the control camera, we use the data logger as an FTP server, on which the camera places an image every hour. The data logger then transmits this image to the FTP server of the laboratory in Grenoble. Since the LoggerNet software is not able to automatically collect files other than data tables, the data logger must therefore perform the PUSH command on the FTP of the laboratory server to retrieve the control images (the data logger can be both server and FTP client). The advantage of this method is that a traditional GPRS modem can be used. A drawback is that the images have to pass through the data logger storage memory, but this does not have much impact on performance and consumption of the control system.

\section{User interface}

A solution with a remote web server was chosen, i.e. it is the server in the lab that generates a web page from the collected data. The RIPLE user interface is developed in R using the Shiny package (JavaScript elements for web interfaces) and dygraphs (graphics). An executable file for this application has been generated to display the results on a dedicated web page to avoid having to install RStudio and to have access to the interface from any terminal equipped with an internet connection.

\subsection{Data visualization}

By default, the interface starts on the "Data visualization" menu, in which all the data transmitted by the RIPLE platform can be seen (the display may take a little time due to the amount of data). It is possible to choose the type of time series to display:

- Fixed time series (default) are four graphs displaying the more common data as shown in Fig. 8, the water level being present in each of these graphs as a common reference. There is a first graph with water level and surface water velocity, a second graph with water level and turbidity, a third graph with water level and water temperature, and a fourth graph with water level and water electrical conductivity. These graphs give an overview of how the station works for the basic variables.

- Customized time series (optional) is a single graph on which it is possible to add two curves on each $y$ axis, among all the variables transmitted by the RIPLE platform as illustrated by Fig. 9 .

All the data that can be displayed is read from the Riple_DATA.txt file (Fig. 6) that is located on the FTP 

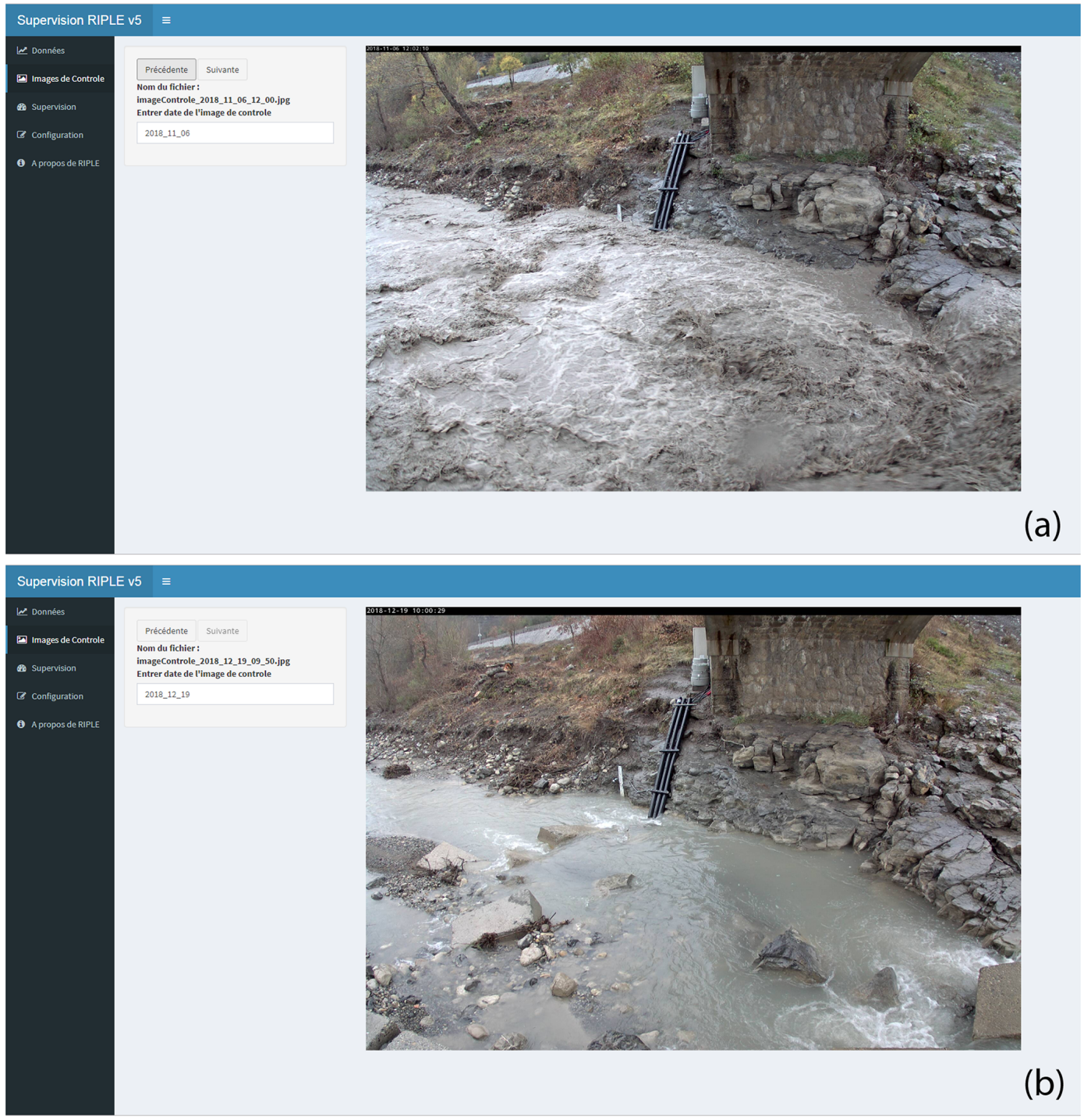

Figure 10. Screenshots of the "Images of control" menu of the user interface at two dates: (a) 6 November 2018 12:00 UTC during a flood and (b) 19 December 2018 10:00 UTC for low-water conditions.

server in Grenoble, i.e. the file uploaded by the RIPLE platform.

- For each type of time series, it is possible to do the following.

To modify the time window to be displayed, there are four options: the last day, the last week, the last month or a manual selection of start and end dates.

- To download the displayed data in an ASCII file in the same format as the one originally produced by the CR6, it is possible to select either specific variables or all variables as in the file uploaded by RIPLE.

\subsection{Control images}

A second menu "Control images" allows users to remotely view the RIPLE platform by displaying the control images that are stored on the FTP server in the laboratory. For example, it allows users to visualize the hydraulic behaviour during floods and at low flows (see Fig. 10). Only fully transmitted images are accessible by default. It is still possible to consult all the control images later on, after having retrieved manually the control images during field visits. All control images are thus stored in an archive directory independent of the FTP server. 


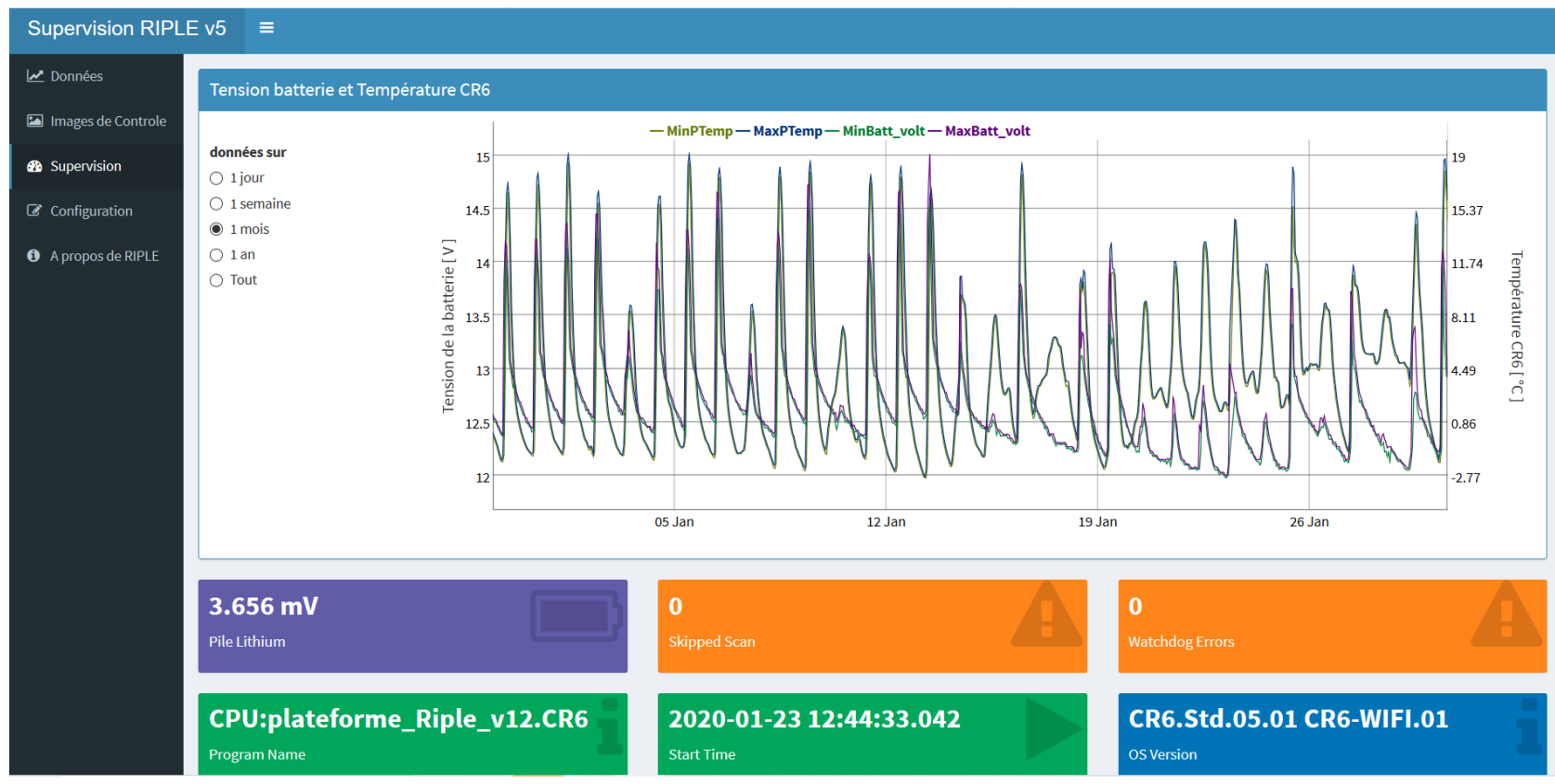

Figure 11. Screenshots of the "Supervision" menu of the user interface. A time series graph is displayed with minimum and maximum battery voltage on the first $y$ axis and min and max air temperature on the second $y$ axis.

\subsection{Supervision}

The "Supervision" menu allows users to remotely control the proper functioning of the platform. The data displayed in this menu are read from the Riple_SAV.txt file that RIPLE uploads to the FTP server (Fig. 6). These are technical variables concerning the control unit (reference identifiers, OS version, internal battery voltage, PakBus address), the name of the current program of the control unit, the status of the power supply and temperature in the electrical cabinet of the RIPLE platform, the data collected (number of measurement, date and time of measurement, watchdog errors, skipped scans, error with the SDA14 card, status of the SD memory card and of the HDD of the hydrophone).

For example, it is possible to check the status of the power supply of the platform by looking at the battery voltage time series (Fig. 11). The temperature measured by the data logger, i.e. the temperature inside the cabinet, must also be controlled, especially in winter (take care if air temperature is below $-10^{\circ} \mathrm{C}$ ) and in summer (take care if air temperature is above $45^{\circ}$ ), because the battery is also present in the electrical box. Based on these thresholds, a SMS alert is sent and the fan is triggered. In addition, if a "Skipped Scan" error message appears, it means that the measurement time of some instruments should be reduced to allow the data logger to perform all the measurements in one cycle.

\subsection{Configuration}

Some parameters of the RIPLE platform can be configured remotely from the "Configuration" menu of the interface (see Fig. 12). This menu is only used by RIPLE's main administrators. To modify other variables, e.g. duration of a scan or measurement time on each instrument, it is necessary to modify the Campbell program of the data logger. It is also possible to do it remotely but it is preferable that it remains exceptional.

\section{Case study}

To date, the RIPLE platform has been tested on two river sites located in the French Alps: the Romanche in Bourg d'Oisans $\left(45.1158^{\circ} \mathrm{N}, 6.0134^{\circ} \mathrm{E}\right.$; elevation $\left.710 \mathrm{~m}\right)$ from September 2016 to July 2018 and the Galabre in La Robine sur Galabre $\left(44.1586^{\circ} \mathrm{N}, 6.2360^{\circ} \mathrm{E}\right.$; elevation $\left.680 \mathrm{~m}\right)$ since October 2018. Photos of the installation sites are shown in Fig. 13.

The first site corresponds to a large embanked river typical of anthropomorphized alpine valleys: the presence of dams upstream and dikes giving rise to a very rectilinear river. The width of the river is about $30 \mathrm{~m}$; the depth is typically between 0.5 and $1 \mathrm{~m}$ at low flows. SSC typically changes between 0 and $10 \mathrm{~g} \mathrm{~L}^{-1}$ all over the year. The platform has benefited from the existing hydrometric station managed by the Electricité de France (EDF) company, including regular discharge measurements and a reference stage-discharge rating curve. 


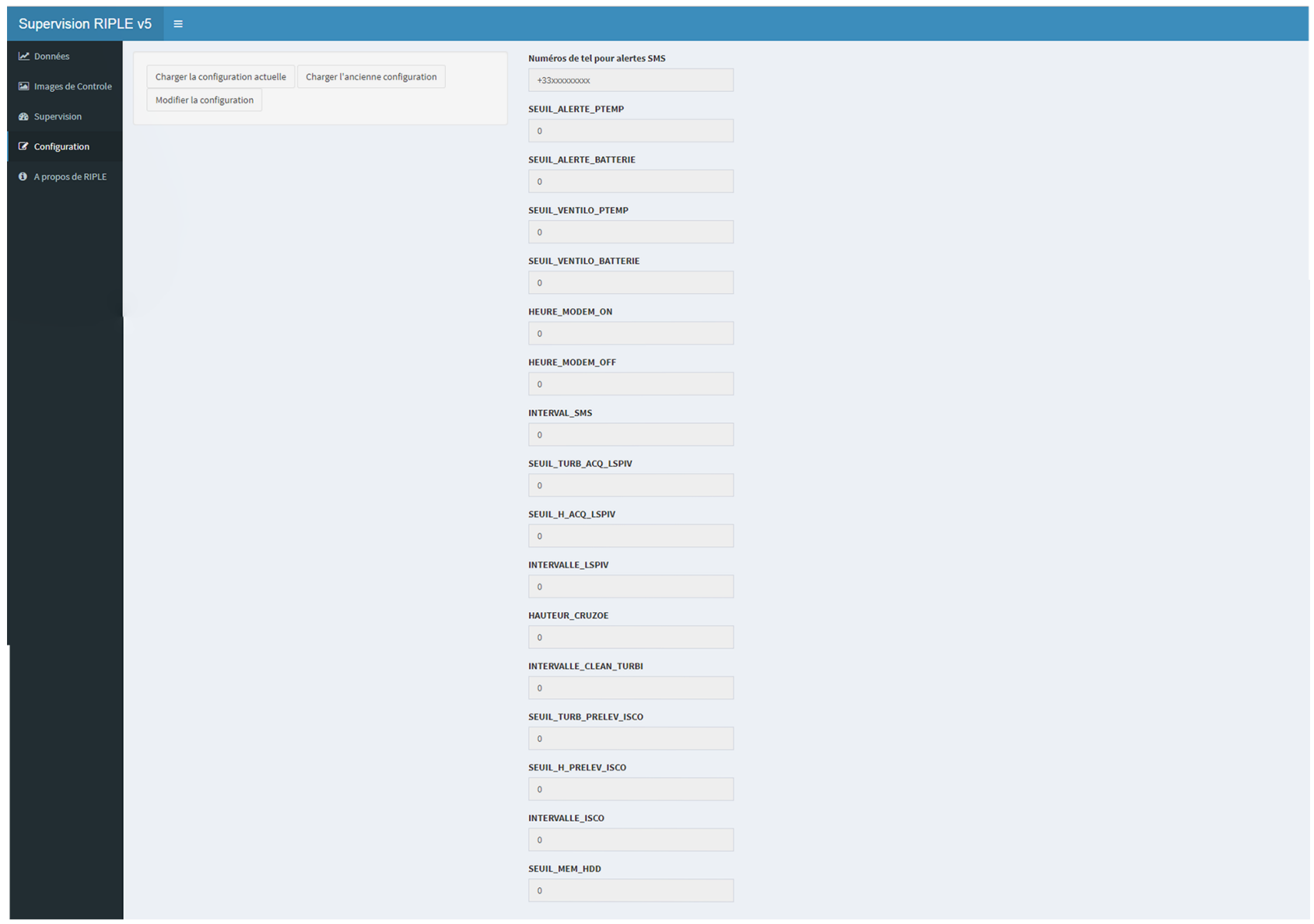

Figure 12. Screenshots of the "Configuration" menu of the user interface. All the external variables of the program that can be modified are given below. "Numéros de tel pour alertes SMS": list of phone numbers that receive SMS alerts sent by the RIPLE platform. "SEUIL_ALERT_PTEMP": threshold on the temperature of the data logger (in degree Celsius) above which an SMS alert is sent. "SEUIL_ALERTE_BATTERIE": threshold on the battery voltage (in volts) below which an SMS alert is sent. "SEUIL_VENTILO_PTEMP": threshold on the temperature of the data logger (in degree Celsius) above which the fan is switched on. "SEUIL_VENTILO_BATTERIE": minimum battery voltage (in volts) to allow the fan to work. "HEURE_MODEM_ON": UTC time at which the RIPLE modem turns on each day, allowing data and images to be transmitted remotely. "HEURE_MODEM_OFF": UTC time at which the RIPLE modem turns off to limit power consumption. "INTERVALLE_SMS": time interval (in hours) between two SMS alerts. "SEUIL_TURB_ACQ_LSPIV": turbidity threshold (in FNU) above which the LSPIV digital camera takes a video. "SEUIL_H_ACQ_LSPIV": water level threshold (in millimetres) above which the LSPIV digital camera takes a video. "INTERVALLE_LSPIV": time interval between 2 consecutive LSPIV video acquisitions (in minutes). Must be a multiple of the scan time (10 min in this study). "HAUTEUR_CRUZOE": difference in elevation between the 0 of the staff gauge and the position of the radar (in millimetres). The water level is then calculated as the difference between "HAUTEUR_CRUZOE" and the distance measured by the radar. "INTERVALLE_CLEAN_TURBI": interval between two consecutive cleaning operations of the turbidimeter using a small brush (in hours). "SEUIL_TURB_PRELEV_ISCO": turbidity threshold above which the automatic water sampler starts its regular sampling (in FNU). "SEUIL_H_PRELEV_ISCO": water level threshold above which the automatic water sampler starts its regular sampling (in millimetres). "INTERVALLE_ISCO": time interval between two samples (in min). Must be a multiple of the scan time (10 min in this study). "SEUIL_MEM_HDD": threshold of the remaining memory on the hydrophone's HDD below which a collection must be planned (in gigabytes). The button "charger la configuration actuelle" triggers the reading of the "config.ini" file on the FTP by the data logger. This file contains the values of the variables currently loaded by the RIPLE platform. The button "charger l'ancienne configuration" triggers the reading of the file "config_old.ini" on the FTP by the data logger, in which there is a backup of $(n-1)$ configuration of the RIPLE platform (in case of false manipulation). The button "modifier la configuration" (ADMIN): after entering the password, it allows users to edit the value of each variable to change the RIPLE platform configuration. 

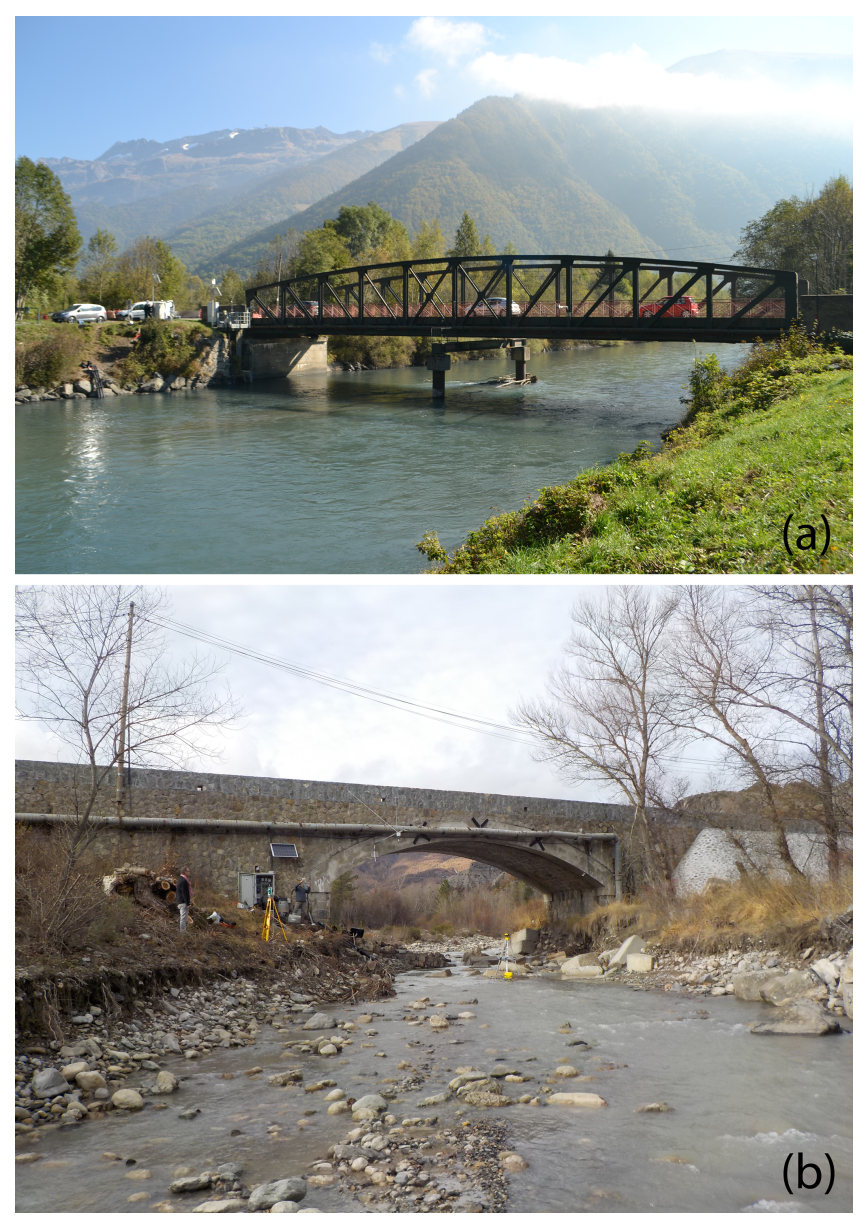

Figure 13. Overview (from downstream) of the river section where the RIPLE platform is located on (a) the Romanche in Bourg d'Oisans $\left(45.1158^{\circ} \mathrm{N}, 6.0134^{\circ} \mathrm{E}\right.$; elevation $\left.710 \mathrm{~m}\right)$ and $(\mathbf{b})$ the Galabre in La Robine sur Galabre $\left(44.1586^{\circ} \mathrm{N}, 6.2360^{\circ} \mathrm{E}\right.$; elevation $680 \mathrm{~m})$.

The second site corresponds to an ungauged site located in a more pristine river in the Southern Alps where sediment loads can be high ( $\max \mathrm{SSC} \sim 360 \mathrm{~g} \mathrm{~L}^{-1}$ ) (Esteves et al., 2019), due to the presence of numerous active badlands. The width of the river is about $10 \mathrm{~m}$; the depth is typically $0.1-0.2 \mathrm{~m}$ at low flows. The station also benefited from a hydro-sedimentary station located $2.5 \mathrm{~km}$ upstream (Esteves et al., 2019), managed since 2007 by the IGE and belonging to the Draix-Bléone Observatory and the research infrastructure OZCAR (Gaillardet et al., 2018).

During these 2 years of testing on two sites, the platform has worked properly, recording a large data set that will be of great interest for the understanding of sediment transport processes in alpine rivers. Figure 14 shows the raw data measured by six sensors for the event of 8 to $9 \mathrm{Au}-$ gust 2017 on the Romanche river in Bourg d'Oisans. The data are provided by the following sensors: water level radar, surface velocity radar, SuSix MJK turbidity sensor, conduc- tivity probe, echo sounder and hydrophone. Figure 14 focuses on the same flood event as Fig. 9, which was only a screenshot of the user web interface. Additionally, the videos (provided by the large-scale particle image velocimetry digital camera), photos (provided by the control camera), the two text files "Riple_DATA.txt" (data from all instruments) and "Riple_SAV.txt" (data that enable users to remotely control the proper functioning of the platform), and the raw data of the hydrophone are open-access data for this flood event through the following link: https://doi.osug.fr/data/public/ RIPLE_8to9August2017/, last access: 11 March 2020. This provides a comprehensive picture of the data produced by the station in terms of formats, file sizes and data quality.

The use of RIPLE data is in progress. For example, a current work is being done to combine radar surface velocity measurements with LSPIV velocity measurements to estimate the mean channel velocity and identify the moments when the geometry of the river is significantly modified by deposition and erosion processes.

\section{Conclusions and outlook}

The characteristics of the presented platform dedicated to monitoring erosion in mesoscale rivers result from a 15-year expertise in hydrometric and sediment measurements within the IGE laboratory and more broadly within the research laboratories in the Grenoble and Lyon communities and local companies such as EDF. The platform has been designed to be applied preferably to rivers in mountainous areas, but it is adjustable and transferable to lowland rivers. Through this study, emphasis was put on water discharge as this elementary variable is not trivial to monitor in situ. Further developments are needed to improve this measurement, especially in rivers where geomorphological processes are very active. A future objective is to develop methods to continuously and directly access discharge data, with a very limited use of gauging and human resources. In addition to the set of measurements provided by the presented platform, a major challenge for the next decade will be the development of methods, allowing users to monitor continuously the bathymetry within the river cross section.

For fine sediment transport, the generalization of the use of the turbidimeter associated with automatic river water sampling for the calibration of turbidity-SSC relationships has allowed for a fairly rapid extension of the monitoring of suspended sediment fluxes during the last decades. However, it is still necessary to improve the spatialization of this measurement within the river cross section, particularly in the case of coarse silt- or sandy-sized particles, which often do not have a homogeneous concentration profile within the water column but rather an increasing concentration profile with depth. It seems necessary to develop non-intrusive technologies for the measurement of suspended sediment fluxes to increase the robustness of the measurement and reduce in 

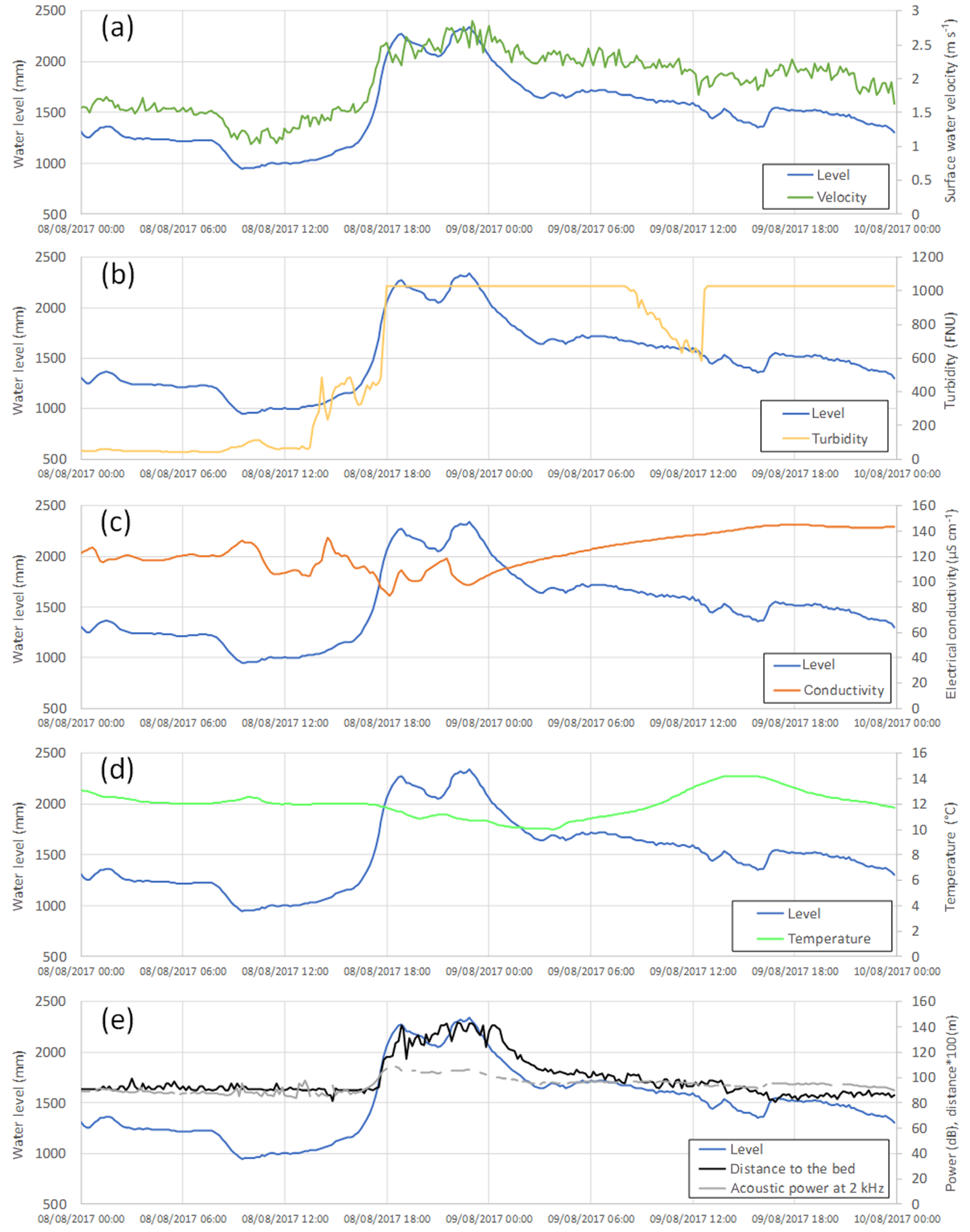

Figure 14. Raw data derived from the "Riple_DATA.txt" file for the 8 to 9 August 2017 in Bourg d'Oisans (Romanche river). (a) Time series of water level and surface water velocity. (b) Time series of water level and turbidity (SuSix MJK). Due to an inappropriate parameterization of the sensor, there is saturation of the signal above 1000 FNU. (c) Time series of water level and electrical conductivity. (d) Time series of water level and temperature. (e) Time series of water level, distance from the echo sounder to the riverbed and acoustic power at $2 \mathrm{kHz}$ measured by the hydrophone. 
situ maintenance. Furthermore, the measurement of the physical characteristics of particles is important because it provides information on transport capacity and deposition processes, on the spatial origin of eroded particles and indicates the propensity of particles to transport adsorbed substances (nutrients, metals, organic products, microorganisms, micro plastics, etc.). These measurements must be performed under conditions that are close to the in situ environment to avoid subsequent flocculation or disaggregation processes.

Concerning coarse sediment transported by bedload, recent metrological developments make it possible to start considering continuous and high frequency monitoring of fluxes and physical characteristics of particles (size distribution) using proxies and inversion models. Passive acoustic and passive seismic monitoring methods are experiencing on-going developments. The first results point to a promising future, although the difficulty lies in validating these methods. Indeed, in situ sampling of transported coarse particles is difficult to carry out and cannot be automated. In this study, the choice was made to integrate passive acoustics technology. These measurements of bedload correspond to a strong demand from the scientific community and more generally from society.

Finally, water quality is partially taken into account in the RIPLE platform through the measurement of electrical conductivity and water temperature and also through the automatic sampling of river water which allows workers, after a filtration step in the laboratory, to carry out any type of analysis from the filtered phase, the so-called dissolved phase (chemical, microbiological, DNA, etc.). Automatic sampling makes it possible to collect water during flood periods or during low-water conditions. The collected samples are also useful for performing analyses (chemical, microbiological, DNA, etc.) on the particulate phase.

In the end, we want to show that the RIPLE platform is a unifying tool that contributes to multidisciplinary studies on understanding the functioning of the critical zone. This is the way this tool has been designed and will continue to evolve. The RIPLE platform is in constant evolution: new innovative instruments are integrated when they have been validated and are in a development phase that allows their integration. Recent examples of integration are the SCAF and the hydrophone. Remote sensing instruments (e.g. radiometers) could also be added to perform non-intrusive turbidity measurements. RIPLE is an autonomous low-power instrument platform which transmits real-time data to a remote server, and it can be controlled remotely, enabling users to fully exploit its potential. The visualization software interface that has been developed allows for an easy follow-up of all measured variables and a beginning of data quality control.

The CRITEX project ("Challenging equipments for the temporal and spatial exploration of the Critical Zone at the catchment scale") has made it possible to purchase an aquatic drone, the FoRiver 1, manufactured by RiverDrone SARL, which offers the opportunity to plan spatial campaigns of certain variables at "hot moments" (low water level, flood, hydraulic flushing). The aquatic drone can thus carry submerged instruments (e.g. conductivity probe, turbidimeter, echo sounder, hydrophone, automatic sampler) to perform measurement campaigns of the same variables as those measured by the RIPLE platform at other points in the cross section or at other points in the profile along the river at different moments.

Data availability. The underlying research data of the article are accessible through the following link: https://doi.osug.fr/data/ public/RIPLE_8to9August2017/(OSUG, 2020).

Author contributions. YM developed and implemented the integration of the RIPLE platform and developed the visualization interface. ME and GN supervised the work of YM. TG contributed to the integration of the hydrophone into RIPLE. CL and BM contributed to the integration of SCAF into RIPLE. AH contributed to the integration of the control camera and the LSPIV camera into RIPLE. YM and GN supervised the installation of RIPLE on the Romanche site, with the help of the IGE technical service. RB and GN supervised the installation of RIPLE on the Galabre site, with the help of the IGE technical service. RB and GF are responsible for the maintenance of RIPLE. RB supervises RIPLE on a daily basis. GN wrote the article using as main basis the technical documentation of the platform written by YM. All the co-authors reviewed the document and contributed more specifically to certain sections.

Competing interests. The authors declare that they have no conflict of interest.

Acknowledgements. Yoann Michielin benefited from an engineer contract from the CRITEX project. The work of Thomas Geay was funded by a research program between Electricité de France (EDF) and Université de Grenoble (GIPSA-Lab/IGE). The development of this platform was carried out with the support of the technical service of the IGE. Most of the instruments presented in this study are the property of the CNRS. They are part of the national park of instruments for the study of the critical zone set up as part of the CRITEX project.

The authors thank Norbert Silvera for his help in integrating the PASS sampler into the RIPLE platform. The authors also thank the French research infrastructure OZCAR (Observatoires de la Zone Critique, Applications et Recherche), the Draix-Bléone Observatory, EDF, the AD Isère Drac Romanche and the department of Alpes-de-Haute-Provence for allowing the RIPLE platform to be installed on the Romanche and Galabre rivers.

Financial support. This research was supported by the EQUIPEX CRITEX project (grant no. ANR-11-EQPX-0011, PIs Jérôme Gaillardet and Laurent Longuevergne). The deployment of the RIPLE platform in the field was also supported by Labex OSUG@2020 
(grant no. ANR10 LABX56) and the Institut National des Sciences de l'Univers (grant no. INSU/CNRS).

Review statement. This paper was edited by Anette Eltner and reviewed by John Gray and one anonymous referee.

\section{References}

Aigner, J., A. Kreisler, R. Rindler, C. Hauer, and Habersack, H.: Bedload pulses in a hydropower affected alpine gravel bed river, Geomorphology, 291, 116-127, https://doi.org/10.1016/j.geomorph.2016.05.015, 2017.

Bellino I., Bergougnoux L., Misguich-Ripault J., and Firpo J-L.: Particle size effects on an optical fiber sensor response, Powder Technol., 115, 68-74, 2001.

Bergougnoux, L.: Diagnostic optique pour la mesure de concentration de matières en suspension, Ph.D. thesis, Aix-Marseille Université, ISBN: $9781847190970,1995$.

Bergougnoux L., Misguich-Ripault J., and Firpo J-L: Characterization of an optical fiber bundle sensor, Rev. Sci. Instrum., 69, 1985-1990, 1998.

Borga, M., Stoffel, M., Marchi, L., Marra, F., and Jakob, M.: Hydrogeomorphic response to extreme rainfall in headwater systems: Flash ?oods and debris flows, J. Hydrol., 518, 194-205, https://doi.org/10.1016/j.jhydrol.2014.05.022, 2014.

Brantley, S. L., DiBiase, R. A., Russo, T. A., Shi, Y., Lin, H., Davis, K. J., Kaye, M., Hill, L., Kaye, J., Eissenstat, D. M., Hoagland, B., Dere, A. L., Neal, A. L., Brubaker, K. M., and Arthur, D. K.: Designing a suite of measurements to understand the critical zone, Earth Surf. Dynam., 4, 211-235, https://doi.org/10.5194/esurf-4-211-2016, 2016.

Camenen, B., Naudet, G., Dramais, G., Coz, J. L., and Paquier, A.: A multi-technique approach for evaluating sand dynamics in a complex engineered Piedmont river system, Sci. Total. Environ., 657, 485-497, https://doi.org/10.1016/j.scitotenv.2018.11.394, 2019.

Clauer, C. R., Kim, H., Deshpande, K., Xu, Z., Weimer, D., Musko, S., Crowley, G., Fish, C., Nealy, R., Humphreys, T. E., Bhatti, J. A., and Ridley, A. J.: An autonomous adaptive low-power instrument platform (AAL-PIP) for remote high-latitude geospace data collection, Geosci. Instrum. Method. Data Syst., 3, 211-227, https://doi.org/10.5194/gi-3-211-2014, 2014.

Comiti, F., Marchi, L., Macconi, P., Arattano, M., Bertoldi, G., Borga, M., Brardinoni, F., Cavalli, M., D’Agostino, V., Penna, D., and Theule, J.: A new monitoring station for debris flows in the European Alps: first observations in the Gadria basin, Nat. Hazards, 73, 1175-1198, https://doi.org/10.1007/s11069014-1088-5, 2014.

Corenblit, D., Tabacchi, E., Steiger, J., and Gurnell, A.M.: Reciprocal interactions and adjustments between fluvial landforms and vegetation dynamics in river corridors: A review of complementary approaches, Earth-Sci. Rev., 84, 56-86, https://doi.org/10.1016/j.earscirev.2007.05.004, 2007.

Costa, J. E., Cheng, R. T., Haeni, F. P., Melcher, N., Spicer, K. R., Hayes, E., Plant, W., Hayes, K., Teague, C., and Barrick, D.: Use of radars to monitor stream discharge by noncontact methods, Water Resour. Res., 42, W07422, https://doi.org/10.1029/2005WR004430, 2006.

Esteves, M., Legout, C., Navratil, O., and Evrard, O.: Medium term high frequency observation of discharges and suspended sediment in a Mediterranean mountainous catchment, J. Hydrol., 568, 562-574, https://doi.org/10.1016/j.jhydrol.2018.10.066, 2019.

Frings, R. M., Gehres, N., Promny, M., Middelkoop, H., Schüttrumpf, H., and Vollmer, S.: Today's sediment budget of the Rhine River channel, focusing on the Upper Rhine Graben and Rhenish Massif, Geomorphology, 204, 573-587, https://doi.org/10.1016/j.geomorph.2013.08.035, 2014.

Gaillardet, J., Braud, I., Hankard, F., et al.: OZCAR: the French network of critical zone observatories, Vadose Zone J., 17, 180067, https://doi.org/10.2136/vzj2018.04.0067, 2018.

Geay, T., Belleudy, P., Gervaise, C., Habersack, H., Aigner, J., Kreisler, A., Seitz, H., and Laronne, J. B.: Passive acoustic monitoring of bed load discharge in a large gravel bed river, J. Geophys. Res.-Earth, 21, 528-545, https://doi.org/10.1002/2016JF004112, 2017a.

Geay, T., Belleudy, P., Laronne, J. B., Camenen, B., and Gervaise, C.: Spectral variations of underwater river sounds, Earth Surf. Proc. Land., 42, 2447-2456, https://doi.org/10.1002/esp.4208, 2017b.

Gimbert, F., Fuller, B. M., Lamb, M. P. , Tsai, V. C., and Johnson, J. P. L.: Particle transport mechanics and induced seismic noise in steep flume experiments with accelerometerembedded tracers, Earth Surf. Proc. Land., 44, 219-241, https://doi.org/10.1002/esp.4495, 2018.

Gray, J. R. and Simões, F. J. M.: Estimating sediment discharge, in: Sedimentation Engineering - Processes, Measurements, Modeling, and Practice, Manual 110, edited by: Garcia, M., American Society of Civil Engineers, 1067-1088, available at: http: //water.usgs.gov/osw/techniques/Gray_Simoes.pdf (last access: 12 March 2020), 2008.

Gray, J. R. and Gartner, J. W.: Technological advances in suspended-sediment surrogate monitoring, Water Resour. Res., 45, W00D29, https://doi.org/10.1029/2008WR007063, 2009.

Gray, J. R., Laronne, J. B., and Marr, J. D. G.: Bedloadsurrogate monitoring technologies, U.S. Geological Survey Scientific Investigations Report 2010-5091, https://doi.org/10.3133/sir20105091, 2010.

Griffiths, R. E., Topping, D. J., Anderson, R. S., Hancock, G. S., and Melis, T. S.: Design of a sediment-monitoring gaging network on ephemeral tributaries of the Colorado River in Glen, Marble, and Grand Canyons, Arizona, U.S. Geological Survey Open File Report 2014-1137, https://doi.org/10.3133/ofr20141137, 2014.

Hauet, A., Kruger, A., Krajewski, W. F., Bradley, A., Muste, M. and Creutin, J. D.: Experimental system for real-time discharge estimation using an image-based method, J. Hydrol. Eng., 13, 105-110, 2008.

Huon, S., Evrard, O., Gourdin, E., Lefèvre, I., Bariac, T., Reyss, J. L., des Tureaux, T. H., Sengtaheuanghoung, O., Ayrault, S., and Ribolzi, O.: Suspended sediment source and propagation during monsoon events across nested sub-catchments with contrasted land uses in Laos, J. Hydrol. Reg. Stud., 9, 69-84, 2017.

Julien, P.-Y. (Eds.): Erosion and sedimentation, Cambridge University Press, 286 pp. https://doi.org/10.1017/CBO9781139174107, 1995. 
ISO 4365: International Organization for Standardization: Liquid flow measurement in open channels - Sediment in streams and canals - Determination of concentration, particle size distribution and relative density, ISO 4365, Geneva, 2005.

ISO 748: International Organization for Standardization: Hydrometry - Measurement of liquid flow in open channels using currentmeters or floats, ISO 748:2007, Geneva, 2007.

Le Boursicaud, R., Pénard, L., Hauet, A., Thollet, F., and Le Coz, J.: Gauging extreme floods on YouTube: application of LSPIV to home movies for the post-event determination of stream discharges, Hydrol. Process., 30, 90-105, https://doi.org/10.1002/hyp.10532, 2016.

Le Coz, J., Hauet, A., Pierrefeu, G., Dramais, G., and Camenen, B.: Performance of image-based velocimetry (LSPIV) applied to flash-flood discharge measurements in Mediterranean rivers, J. Hydrol., 394, 42-52, 2010.

Leduc, P., Ashmore, P., and Sjogren, D.: Technical note: Stage and water width measurement of a mountain stream using a simple time-lapse camera, Hydrol. Earth Syst. Sci., 22, 1-11, https://doi.org/10.5194/hess-22-1-2018, 2018.

Lee, C. and Foster, G.: Assessing the potential of reservoir outflow management to reduce sedimentation using continuous turbidity monitoring and reservoir modelling, Hydrol. Proces., 27, 14261439, https://doi.org/10.1002/hyp.9284, 2013.

Legout C., Droppo I.G., Coutaz J., Bel C., and Jodeau M.: Assessment of erosion and settling properties of fine sediments stored in cobble bed rivers: the Arc and Isère alpine rivers before and after reservoir flushing, Earth Surf. Proc. Land., 43, 1295-1309, https://doi.org/10.1002/esp.4314, 2018.

Levesque, V. A. and Oberg, K. A.: Computing discharge using the index velocity method, U.S. Geological Survey Techniques and Methods 3-A23, https://doi.org/10.3133/tm3A23, 2012.

Mano, V.: Processus fondamentaux conditionnant les apports de sédiments fins dans les retenues - optimisation des méthodes de mesure et modélisation statistique, Ph.D. thesis, Université Joseph-Fourier, available at: https://tel.archives-ouvertes.fr/ tel-00365349 (last access: 2 October 2019, 2008.

Marineau, M. D., Wright, S. A., and Gaeuman, D.: Calibration of sediment-generated noise measured using hydrophones to bedload transport in the Trinity River, California, USA, in: Proceedings of River Flow Conf., Iowa City, USA, 11-14 July 2016, 1519-1526, 2016.

Morlock, S. E., Nguyen, H. T., and Ross, J. H.: Feasibility of Acoustic Doppler Velocity Meters for the Production of Discharge Records from U.S. Geological Survey Streamflow-Gaging Stations: U.S. Geological Survey Water-Resources Investigations Report 2001-4157, https://doi.org/10.3133/wri20014157, 2002.

Morris, G. L. and Fan, J. (Eds.): Reservoir sedimentation handbook: design and management of dams, reservoirs, and watersheds for sustainable use, McGraw-Hill, New York, USA, 848 pp., 1998.

Morschhauser, A., Haseloff, J., Bronkalla, O., MüllerBrettschneider, C., and Matzka, J.: A low-power data acquisition system for geomagnetic observatories and variometer stations, Geosci. Instrum. Method. Data Syst., 6, 345-352, https://doi.org/10.5194/gi-6-345-2017, 2017.

M-Tropics, Service de données OMP (SEDOO): Stations and acquisition parameters, available at: https: //mtropics.obs-mip.fr/stations-and-acquisition-parameters/
laos-lak-sip-catchment/?noredirect=en_US (last access: 16 January 2020), 2017.

Mueller, P., Thoss, H., Kaempf, L., and Güntner, A.: A Buoy for Continuous Monitoring of Suspended Sediment Dynamics, Sensors, 13, 13779-13801, https://doi.org/10.3390/s131013779, 2013.

Musko, S. B., Clauer, C. R., Ridley, A. J., and Kennneth, L. A.: Autonomous low-power magnetic data collection platform to enable remote high latitude array deployment, Rev. Sci. Instrum., 80, 044501, https://doi.org/10.1063/1.3108527, 2009.

Muste, M., Fujita, I., and Hauet, A.: Large-scale particle image velocimetry for measurements in riverine environments, Water Resour. Res., 44, W00D19, https://doi.org/10.1029/2008WR006950, 2008.

Nord, G., Gallart, F., Gratiot, N., Soler, M., Reid, I., Vachtman, D., Latron, J., Martín Vide, J. P., and Laronne, J. B.: Applicability of acoustic Doppler devices for flow velocity measurements and discharge estimation in flows with sediment transport, J. Hydrol., 509, 504-518, https://doi.org/10.1016/j.jhydrol.2013.11.020, 2014.

Navratil, O., Esteves, M., Legout, C., Gratiot, N., Némery, J., Willmore, S., and Grangeon, T.: Global uncertainty analysis of suspended sediment monitoring using turbidimeter in a small mountainous river catchment, J. Hydrol., 398, 246-259, https://doi.org/10.1016/j.jhydrol.2010.12.025, 2011.

OSUG (Observatoire des Sciences de l'Univers de Grenoble): available at: https://doi.osug.fr/data/public/RIPLE_8to9August2017/, last access: 12 March 2020.

Owens, P. N., Batalla, R. J., Collins, A. J., Gomez, B., Hicks, D. M., Horowitz, A. J., Kondolf, G. M., Marden, M., Page, M. J., Peacock, D. H., Petticrew, E. L., Salomons, W., and Trustrum, N. A.: Fine-grained sediment in river systems: environmental significance and management issues, River Res. Appl., 21, 693-717, https://doi.org/10.1002/rra.878, 2005.

Peters, N., Oppenheimer, C., and Kyle, P.: Autonomous thermal camera system for monitoring the active lava lake at Erebus volcano, Antarctica, Geosci. Instrum. Method. Data Syst., 3, 13-20, https://doi.org/10.5194/gi-3-13-2014, 2014.

Rasmussen, P. P., Gray, J. R., Glysson, G. D., and Ziegler, A. C.: Guidelines and procedures for computing time-series suspended-sediment concentrations and loads from in-stream turbidity-sensor and streamflow data: U.S. Geological Survey Techniques and Methods 3-C4, book 3, chap. 4, 53 pp., https://doi.org/10.3133/tm3C4, 2009.

Recking, A., Liébault, F., Peteuil, C., and Jolimet, T.: Testing bedload transport equations with consideration of time scales, Earth Surf. Proc. Land., 37, 774-789, https://doi.org/10.1002/esp.3213, 2012.

Rennie, C. D., Millar, R. G., and Church, M. A.: Measurement of bed load velocity using an acoustic Doppler current profiler, J. Hydraul. Eng., 128, 473-483, https://doi.org/10.1061/(ASCE)0733-9429(2002)128:5(473), 2002.

Rennie, C. D., Vericat, D., Williams, R. D., Brasington, J., and Hicks, M.: Calibration of acoustic doppler current profiler apparent bedload velocity to bedload transport rate, in: Gravel-Bed Rivers Process Disasters, edited by: Tsutsumi, D., and Laronne, J. B., John Wiley \& Sons Ltd., 209-233, https://doi.org/10.1002/9781118971437.ch8, 2017. 
Renwick, W. H., Smith, S. V., Bartley, J. D., and Buddemeier, R. W.: The role of impoundments in the sediment budget of the conterminous United States, Geomorphology, 71, 99-111, https://doi.org/10.1016/j.geomorph.2004.01.010, 2005.

Ribolzi, O., Evrard, O., Huon, S., de Rouw, A., Silvera, N., Latsachack, K. O., Soulileuth, B., Lefèvre, I., Pierret, A., Lacombe, G., Sengtaheuanghoung, O., and Valentin, C.: From shifting cultivation to teak plantation: Effect on overland flow and sediment yield in a montane tropical catchment, Sci. Rep., 7, 3987, https://doi.org/10.1038/s41598-017-04385-2, 2017.

Roth, D. L., Brodsky, E. E., Finnegan, N. J., Rickenmann, D., Turowski, J. M., and Badoux, A.: Bed load sediment transport inferred from seismic signals near a river, J. Geophys. Res.-Earth, 121, 725-747, https://doi.org/10.1002/2015JF003782, 2016.

Sobieszczyk, S., Uhrich, M. A., and Bragg, H. M: Major turbidity events in the North Santiam River basin, Oregon, water years 1999-2004: U.S. Geological Survey Scientific Investigations Report 2007-5178, 50 pp., https://pubs.usgs.gov/sir/2007/ 5178/pdf/sir20075178.pdf (last access: 11 March 2020), 2007.

Stumpf, A., Augereau, E., Delacourt, C., and Bonnier, J.: Photogrammetric discharge monitoring of small tropical mountain rivers: A case study at Rivière des Pluies, Réunion Island, Water Resour. Res., 52, 4550-4570, https://doi.org/10.1002/2015WR018292, 2016.

Thollet F., Le Coz J., Dramais G., Nord G., Le Boursicaud R., Jacob E., and Buffet A.: Streamflow monitoring at stage/velocity radar stations using the index velocity method, La Houille Blanche, 5, 9-15, https://doi.org/10.1051/lhb/2017038, 2017.

Thorne, P. D. and Foden, D. J.: Generation of underwater sound by colliding spheres, J. Acoust. Soc. Am., 84, 2144-2152, https://doi.org/10.1121/1.397060, 1988.
Tomkins, K. M.: Uncertainty in streamflow rating curves: methods, controls and consequences, Hydrol. Process., 28, 464-481, https://doi.org/10.1002/hyp.9567, 2012.

Tsai, V. C., Minchew, B., Lamb, M. P., and Ampuero, J.P.: A physical model for seismic noise generation from sediment transport in rivers, Geophys. Res. Lett., 39, 2-7, https://doi.org/10.1029/2011GL050255, 2012.

Walling, D. E. and Fang, D.: Recent trends in the suspended sediment loads of the world's rivers, Glob. Planet. Change, 39, 111126, https://doi.org/10.1016/S0921-8181(03)00020-1, 2003.

Welber, M., Le Coz, J., Laronne, J. B., Zolezzi, G., Zamler, D., Dramais, G., Hauet, A., and Salvaro, M.: Field assessment of noncontact stream gauging using portable surface velocity radars (SVR), Water Resour. Res., 52, 1108-1126, https://doi.org/10.1002/2015WR017906, 2016.

Wendling V., Gratiot N., Legout C., Droppo I., Coulaud C., and Mercier B.: Using an optical settling column to assess suspension characteristics within the free, flocculation and hindered settling regimes, J. Soil. Sediment., 15, 1991-2003, https://doi.org/10.1007/s11368-015-1135-1, 2015.

World Meteorological Organization (Ed.): Manual on stream gauging, volume 1 Fieldwork, World Meteorological Organization, WMO-No. 1044, Geneva, Switzerland, 248 pp., 2010. 